\title{
1 Experimental study on the effects of humidity and temperature on aerogel composite 2 and foam insulations ${ }^{1}$
}

3 Jedediah B. Alvey ${ }^{\mathrm{a}}$, Jignesh Patel ${ }^{\mathrm{a}}$, Larry .D. Stephenson ${ }^{\mathrm{a}}$

$4{ }^{a}$ Construction Engineering Research Laboratory, U.S. Army Engineer Research and Development Center, 5 Champaign, IL 61826, USA

\section{Abstract}

Building insulation materials have been subjected to various temperature and humidity conditions and their thermal performance during several weeks of controlled environmental exposure. Several commercially available insulation materials (three aerogel composite blankets, two extruded polystyrene foams (XPS) and one blown polyurethane foam (PUR)) were evaluated. The purpose is to compare performance of newer types (aerogel composites) with established types (foams). Thermal conductivity was measured with a heat flow metering apparatus at one week intervals for five weeks. Insulations were exposed to conditions of $65.6^{\circ} \mathrm{C}$ and $90 \% \mathrm{RH}, 65.6^{\circ} \mathrm{C}$ and $60 \% \mathrm{RH}, 65.6^{\circ} \mathrm{C}$ and $30 \% \mathrm{RH}$, and $32.2^{\circ} \mathrm{C}$ and $90 \% \mathrm{RH}$. Results indicate that humidity levels play a significant role in PUR performance, but not a significant role in XPS performance. The three aerogel composites have mixed results: one has little relationship between moisture content and thermal performance, one is strongly affected by moisture and the remaining is moderately affected by moisture. Fourier infrared spectrometry was performed on some of the materials to observe chemical stability. Results indicate that factors other than moisture content, such as hygroscopy and volume expansion, significantly contribute to thermal performance.

Keywords:

Aerogel, polymer foam, insulation, thermal conductivity, accelerated aging

\section{Introduction}

\subsection{Background}

Energy consumption has heightened significantly over the past few decades, and with the push for energy conservation research has strengthened. Commercial and residential buildings are a large source of energy consumption. In 2012, an estimated 18.9 quadrillion Btu $\left(19.9 \times 10^{15} \mathrm{~kJ}\right)$ were consumed in the residential and commercial sectors of the United States, representing about $1 / 5$ of energy used [1]. Climate control is a major portion of this consumption. Data from 2009 suggests that $48 \%$ of home energy use was for heating and cooling [2], and 2003 data shows that $44 \%$ of energy used in commercial buildings was used for heating and cooling [3]. By using a combination of thermal insulation and air infiltration control, this energy burden can be significantly reduced. Mitigation of energy losses is of particular interest for the Army in various types of structures, both permanent and temporary.

The choice of insulating material used can have a great effect on the energy efficiency of a building in both cooling and heating situations. Many insulating materials have been developed and improved to address the need for better energy efficiency. A selection of some common and some new insulation types were studied. Foams are commonly used in building construction as insulators; two types of rigid, closed cell foams were selected for this study: extruded polystyrene (XPS) and spray polyurethane (PUR). Aerogel composite materials are emerging as high performance insulators. Despite its discovery over eight decades ago [4], use of aerogel as a building material is relatively new, e.g. [5],[6],[7]. Because of its brittleness aerogel must be part of a composite when used in building applications. Aerogel composites consisting of aerogel and lofty fibrous batting (aerogel blankets) were selected for this study. 
Long-term performance is an important consideration for selecting the best insulation for each application. In order to predict long-term performance, this study has performed accelerated aging on the selected insulating materials through exposure to elevated temperature and humidity conditions. Previously published work has shown that fiberglass and XPS insulation retain $97 \%$ of their R-value over several weeks of exposure to $65.6^{\circ} \mathrm{C}$ and $90 \% \mathrm{RH}$, while aerogel blankets and PUR foam experienced $15 \%$ and $27.5 \%$ losses, respectively. In a continuation of these experiments, XPS, PUR and aerogel blankets have been aged at elevated temperature and humidity conditions, with additional measurements taken to determine moisture levels in the samples. The aging conditions were selected to reflect the previous work and allow for parallel work (outside the scope of the current work) of applying time-temperature superposition techniques, as indicated in [8]).

\subsection{Materials}

\subsubsection{Closed Cell Extruded Polystyrene}

Extruded polystyrene is a closed cell foam; the cells are filled with a blowing agent that has thermal conductivity lower than air to improve its thermal properties. It is rigid and can provide some structural support. Frequently, XPS is used as part of an exterior wall panel [9]. The choice of blowing agent has the greatest effect on thermal performance; different blowing agents used to form foams with identical geometries can have significantly different thermal properties. Additionally, long-term performance can vary greatly between blowing agents [10]. Two versions of XPS foam were included in the study, with nominal thicknesses of 2" $(50.8 \mathrm{~mm})$ and $21 / 8^{\prime \prime}(54.0 \mathrm{~mm})$. One version uses a trans-1,3,3,3Tetrafluoroprop-1-ene blowing agent [11]. The other uses a combination of 1-Chloro-1,1-difluoroethane and 1,1,1,2-Tetrafluoroethane [12].

\subsubsection{Closed Cell Spray Polyurethane Foam}

Spray polyurethane is sprayed into place as an expanding multi-component mixture. Like XPS, the closed cells are filled with a blowing agent to improve thermal properties. It can be applied to a variety of surfaces and is typically applied to the interior cavities of an unfinished wall or ceiling. Due to its adherence to the structure, it can provide additional structural support and an improved air barrier [13]. One version of PUR foam was included in the study, which uses 1,1,1,3,3-Pentafluoropropane as a blowing agent [14].

\subsubsection{Aerogel Composite}

Aerogel is an extremely low density open cell material with cells on the nano scale. It is created from supercritical drying of various types of gels, and is most commonly made from silica gel. Aerogel composites typically involve molding a gel around a supporting structure (e.g. lofty fibrous batting, xonotlite-type calcium silicate [15]) followed by the drying process. Three versions of aerogel composite blankets were studied-consisting of various combinations of PET, fibrous glass, and/or other polyolefinand silica aerogel. One of two methods for making aerogel blankets is typically used. The first is begun by creating a sol (precursor to the gel) within the voids of the batting material in a mold. The gel is formed and at this stage dopants, additives and treatments can be applied. The formation is subsequently dried forming the aerogel around the supporting material [16]. The other method nests previously formed aerogel particles in a web of bicomponent fibers. The bicomponent fibers are such that part of the fiber melts at a low enough temperature to bond the fibers to each other and to the aerogel particles [17]. Of the selected aerogel blankets, two were of the former type and one was of the latter type. The aerogels of all three are hydrophobic, being made from trimethylsilylated silica gel $[18],[19],[20]^{2}$. 
Several studies have presented thermal models of aerogel composite insulation materials. Zhao et al [21] used a numerical model to determine the effective thermal conductivity of fiber loaded silica aerogel for different temperatures, densities and fiber geometry, amount and orientation. Both Xie [22] and Wei [15] give complete models to calculate overall conductivities of their composites, giving consideration to both solid conduction and radiation. Xie's modeling is for aerogels doped with opacifier particles and fibers; Wei's modeling is for xonotlite-aerogel composite materials. Herseini et al. [23] examined commercially available aerogel/fiber composites for their performance under compressive cycling.

The current work considers overall thermal conductivity of some commercially available aerogel/fiber composites that were subjected to aging at elevated temperatures and humidity conditions, and seeks to determine the mechanisms by which they degrade. It is suggested that future work consider mathematical modeling of such degradation.

\section{Methods}

Samples of three versions of aerogel blanket insulations (labeled $A A, A B$, and $A C$ ), two types of extruded polystyrene foam (labeled XPA and XPB), and one type of closed cell spray polyurethane foam were prepared for aging simulation experiments. Samples tested were square, measuring 30 inches (762 $\mathrm{mm}$ ) along each width (for best fit in equipment), and thicknesses were as commercially available. In some cases, a sample consisted of two pieces totaling 30 inches $(760 \mathrm{~mm})$ square. Each type of insulation was subjected to tests at multiple environmental conditions. For each environmental condition and each type of insulation, at least three samples were evaluated, except where noted. Aerogels were exposed at $65.6^{\circ} \mathrm{C}$ and $90 \% \mathrm{RH}, 65.6^{\circ} \mathrm{C}$ and $30 \% \mathrm{RH}$ and $32.2^{\circ} \mathrm{C}$ and $90 \% \mathrm{RH}$. Polyurethane foams were exposed at $65.6^{\circ} \mathrm{C}$ and $90 \% \mathrm{RH}, 65.6^{\circ} \mathrm{C}$ and $30 \% \mathrm{RH}$ and an individual sample at $65.6^{\circ} \mathrm{C}$ and $60 \% \mathrm{RH}$. One Sample of each type of polystyrene foam was exposed at $65.6^{\circ} \mathrm{C}$ and $90 \% \mathrm{RH}$, and one of each at $65.6^{\circ} \mathrm{C}$ and $60 \% \mathrm{RH}$. Samples were placed in the chamber at time 0 and removed at one week intervals to take measurements. Samples were kept in the environmental chamber through five weeks.

Prior to exposure in an environmental chamber, initial measurements were taken for baseline comparison. Before baseline measurements, samples were stored in laboratory where conditions ranged from approximately $15-25^{\circ} \mathrm{C}$ and $20-40 \%$ RH. A Laser Comp FOX $801^{2}$ heat flow meter apparatus (HFMA) with associated WinTherm32 software was used to find thickness, apparent thermal conductivity and heat flux at a mean temperature of $30.5^{\circ} \mathrm{C}$ with $\Delta \mathrm{T}=25^{\circ} \mathrm{C}$ between plates. Laser Comp indicates thermal conductivity measurement accuracy of $\pm 1 \%$. Mass was measured on a digital scale with an accuracy of $\pm 0.2 \mathrm{~g}$, which is about $0.7 \%$ of the mass of the lightest material in this study. A set of measurements consisted of: mass before and after HFMA, and measurements of apparent thermal conductivity, heat flux, sample thickness in the HFMA. Additionally, the ambient temperature and relative humidity and times of day were recorded for each set of measurements. The initial measurements were repeated three times and the average was used as the baseline.

After baseline measurements were taken, samples were then placed in a Cincinnati Subzero ${ }^{2}$ ZP32 environmental chamber, where conditions were held constant for several weeks $\left( \pm 0.5^{\circ} \mathrm{C}\right.$ and $\pm 3 \% R H$ ). Samples were removed at weekly intervals during the testing period to collect and record measurements, and were replaced in the environmental chamber after measurements were taken. Typical measurements required the sample to be removed from the chamber for 2-3 hours.

Measurement of moisture content was implicitly estimated by comparing mass measurements to the pre-environmental chamber mass of the same sample. Mass was measured upon removal from the chamber and upon completion of thermal measurements in the HFMA. Moisture content was taken as the difference between the baseline mass and the average of the mass upon removal from and the mass prior to placement back in the environmental chamber. 
Early tests at the higher temperatures of the closed cell spray PUR foam resulted in samples warped too badly to conduct measurements in the HFMA. To prevent warping, a nominal thickness of 1 " (24.5 $\mathrm{mm}$ ) of foam was sprayed onto $30 \mathrm{in.} \times 30 \mathrm{in}$. $(76 \mathrm{~cm} \times 76 \mathrm{~cm})$ sections of 3/4" $(19 \mathrm{~mm})$ thick plywood. All PUR samples in this study are a composite of PUR foam on a plywood substrate. Blank pieces of plywood were also subjected to the same environmental conditions as part of an attempt to subtract the thermal effects of the plywood from the combined plywood and foam samples.

The plywood itself is affected by moisture, which contributes to the overall degradation of the PUR/plywood combination. In order to distinguish between the effects of PUR and plywood, blank samples of plywood were exposed and measured at the same conditions and time intervals. Treating this as a thermal circuit model with the two components in series [24], the plywood effects can be mathematically removed using the relationship

$$
\rho_{f}=\Delta T\left(\frac{1}{q_{c}}-\frac{1}{q_{w}}\right) / t_{f}=\frac{1}{k_{f}}
$$

Here $\rho_{\mathrm{f}}$ is the thermal resistivity of the foam (thermal resistance per unit thickness), $\Delta \mathrm{T}$ is the temperature difference across the HFMA plates, $\mathrm{q}_{\mathrm{c}}$ is the heat flux through the PUR/plywood composite, $\mathrm{q}_{\mathrm{w}}$ is the heat flux through plywood alone, $\mathrm{t}_{\mathrm{f}}$ is the thickness of the foam and $\mathrm{k}_{\mathrm{f}}$ is the thermal conductivity of the foam. To verify the validity of this approach, measurements were taken on a sample of combined PUR and plywood (post-environmental chamber) followed by the separation and individual measurements of the two components. The thermal resistivity for the foam obtained from equation ( 1 ) is compared with results from physically removing the foam from the plywood in Table 2. Further comparisons were made using calculations with several other samples of blank plywood, resulting in an average calculated thermal resistivity of $4.13 \mathrm{ft}^{2} \cdot{ }^{\circ} \mathrm{F} \cdot \mathrm{hr} / \mathrm{BTU} \cdot \mathrm{in}(28.6 \mathrm{~K} \cdot \mathrm{m} / \mathrm{W})$, with a standard deviation of $0.09 \mathrm{ft}^{2} \cdot{ }^{\circ} \mathrm{F} \cdot \mathrm{hr} / \mathrm{BTU} \cdot \mathrm{in}(0.62 \mathrm{~K} \cdot \mathrm{m} / \mathrm{W})$. This approach appears to give good results for $\mathrm{R}$ values of PUR; however, due to much greater variation in the mass of the plywood samples, the amount of individual moisture content cannot be mathematically estimated. Considering these results, data presented herein will represent samples of composite PUR and plywood, but it is noted that all of the thermal resistivity values of PUR itself are calculated to be approximately $40 \%$ higher than the combined PUR and plywood values.

Some Fourier transform infrared (FTIR) spectrometry was performed on the aerogel blankets. Small $(1 \mathrm{~cm} \times 2 \mathrm{~cm})$ samples of each type of blanket were subjected to $65.6^{\circ} \mathrm{C}$ and $90 \% \mathrm{RH}$ and $65.6^{\circ} \mathrm{C}$ and $30 \% \mathrm{RH}$ conditions. In each environmental condition, for each blanket type, one sample was taken out at one week and analyzed, then another sample was taken out at five weeks and analyzed, by FT-IR 4100 ,Tokyo, Japan. These were later compared with baseline (no exposure) samples. Aerogels were also observed under scanning electron microscope. Samples were prepared and aged in the same manner as the FTIR samples for $65.6^{\circ} \mathrm{C}$ and $90 \% \mathrm{RH}$ conditions.

\section{Results and Discussion ${ }^{3}$}

\subsection{Physical changes}

No significant physical changes were apparent in the aerogel and polystyrene materials, while polyurethane experienced major physical changes. In all three environmental conditions the samples became discolored, changing from light yellow to dark yellow during exposure (mild discoloration also occurred during storage). Some volume expansion occurred (see Figure 1), being more extreme during the higher humidity conditions. Blistering occurred in the $65.6^{\circ} \mathrm{C}$ and $90 \% \mathrm{RH}$ conditions, as shown in Figure 2. Expansion and blistering typically occurred within the first week of exposure. Some samples expanded enough that the material needed to be trimmed to fit in the HFMA for measurements. In 
those cases, the mass of the trimmed material was measured and taken into account. The sample shown in Figure $2 b$ was so extreme that no thermal conductivity measurements could be taken beyond the baseline values. It is noted that samples that were stored (in a laboratory environment) for longer periods of time prior to exposure in the environmental chamber were more prone to blistering and expansion.

\subsection{Thermal performance and Moisture content}

Both types of XPS experienced $<1 \%$ change in thermal conductivity by the end of five weeks of exposure at $65.6^{\circ} \mathrm{C}$ and $90 \% \mathrm{RH}$, which is insignificant compared to the uncertainty of the HFMA. They both showed small decreases in mass during that time. The XPB had a $0.4 \%$ decrease in thermal conductivity with a $1.4 \%$ loss in mass and XPA had a $1 \%$ decrease in thermal conductivity with a $0.5 \%$ loss in mass (see Figure 3 ). At $65.6^{\circ} \mathrm{C}$ and $60 \%$ RH conditions, both types of XPS again experienced little change in thermal conductivity. At the end of five weeks, XPA had a $2 \%$ decrease in thermal conductivity with a $0.7 \%$ loss in mass and XPB had a $0.6 \%$ decrease in thermal conductivity with a $0.5 \%$ loss in mass. Since very little change occurred during the more extreme conditions, and due to limited space in the environmental chamber, it was decided not to perform further testing of XPS at the milder environmental conditions.

All PUR samples were received at the same time and stored until baseline measurements were individually taken prior to aging tests. Figure 4 shows the measured baselines at the indicated number of days from first receiving the samples. The figure also includes the aged data of two of these samples, one at $65.6^{\circ} \mathrm{C}$ and $90 \% \mathrm{RH}$ and the other at $65.6^{\circ} \mathrm{C}$ and $30 \% \mathrm{RH}$. Both samples were then placed back in ambient conditions for several months and measured again. The high humidity sample showed some amount of thermal resistivity recovery, while the low humidity sample continued to degrade, although at a slower rate than when in the environmental chamber. It is interesting to note that the low humidity sample initially increased slightly in thermal resistivity during exposure, and then proceeded to degrade. On the other hand, the high humidity sample initially decreased significantly in thermal resistivity during exposure, while recovering somewhat after removal from the environmental chamber.

Averaged results at $65.6^{\circ} \mathrm{C}$ and $90 \% \mathrm{RH}$ conditions showed that PUR saw the greatest decrease in thermal resistivity, near $10 \%$, as shown in Figure 5 . Error bars represent $90 \%$ confidence intervals based on Student's t-test. All three aerogel blankets had comparable levels of decrease, around $5 \%$, but with $A B$ having much larger variation. After one week of exposure, the thermal resistivity of $A C$ remains nearly constant, while all three of the other insulations continue to decrease through five weeks of exposure. The moisture content of all the insulations at these conditions increased significantly, or decreased slightly. The mass change in PUR was the greatest, near $10 \%$. AB typically saw an increase in mass above $2 \%$, but in some cases there was an insignificant decrease in mass. AA typically had insignificant changes in mass, while AC saw decreases up to about $1 \%$ in most cases. One sample of AC increased in mass by $2.5 \%$, but it is suspected to be a result of condensation from the environmental chamber dripping onto the sample and not a result of typical sorption of water.

At $65.6^{\circ} \mathrm{C}$ and $30 \% \mathrm{RH}$ conditions (see Figure 6), PUR samples showed a typical increase in thermal resistivity of $5 \%$ after one week, then further degradation to a net increase of $3 \%$ after five weeks. Half of the samples of $A A$ increased in thermal resistivity by about $2 \%$, while half decreased by about $2 \%$. $A B$ typically had insignificant change in thermal resistivity $(<0.5 \%)$, but in some cases decreased by $1 \%-1.5 \%$. AC decreased in thermal resistivity by an average of $3.4 \%$. In all three samples the thermal resistivity stayed nearly constant after the first week of exposure. PUR/plywood decreased in moisture content with a mass change of about $1.5 \%$ after one week and decreased only slightly more through five weeks. AA saw an average decrease in mass of $2 \%, A B$ by an average of $1.75 \%$ and $A C$ by an average of $1 \%$, after five weeks of exposure. 
Due to a limited supply of PUR composites and limited testing space, only aerogel blankets were tested at $32.2^{\circ} \mathrm{C}$ and $90 \% \mathrm{RH}$ conditions (see Figure 7); averaged results are as follows: $A B$ had the greatest decrease in thermal resistivity, at $4.25 \%$. AA and $A C$ had similar levels of decrease, near $1.25 \%$. Both AA and $A C$ decreased moisture content, at $2 \%$ and $0.5 \%$ loss of mass, respectively, after five weeks. $A B$ increased in mass to about $1.5 \%$ after one week and remained nearly constant through five weeks.

Figure 8 illustrates the general trend of the effect of moisture on the thermal conductivity of all three aerogel composites and the PUR foam on plywood after one week of exposure. AA, AB and PUR samples show that an increase in moisture effects, in general, an increase in conductivity. With further aging, however, the relationship between thermal conductivity and moisture content is obscured. Figure 9 shows a similar plot, but after five weeks of exposure (four weeks for PUR). Compared to the one week data, the samples have increased significantly in thermal conductivity with only small changes is moisture content. This indicates there are some other mechanisms apart from moisture content that lead to a change in thermal performance. AC shows no clear relationship between moisture and thermal conductivity at either one or five weeks, although a comparable change in thermal conductivity still occurs. Another, possibly separate mechanism affects the thermal conductivity of AC.

\subsection{Cause of degradation}

\subsubsection{Foams}

Since the PUR samples are adhered to plywood substrates, it is difficult to separate the effects of temperature and humidity between the plywood and the PUR. Figure 4 helps to qualitatively distinguish between the materials. In dry conditions, we see that the sample initially increases in thermal resistivity, but then proceeds to degrade. This is a result of the initial drying of the plywood, and then the foam itself degrades beyond that. In contrast, at the higher humidity condition the sample degrades very rapidly initially. Once it is removed from the humidity, some amount of recovery is seen. This can be attributed to the plywood first taking in water due to the high humidity and then drying out once it is removed from the high humidity. It is clear from other studies that the blowing agent used has a significant effect on the performance of foam insulations, both on the gaseous thermal conductivity and in its rate of effusion from the foam cells [25],[26]. The overall decrease in thermal resistivity observed at both conditions is a result of both the loss of blowing agent and the infusion of higher thermal conductivity gases [27], such as air and water vapor. In addition, some sorption of moisture into the cell walls may also contribute to the increase in thermal conductivity. As shown in Figure 1, staining is observed in the aged samples, which indicates that moisture is absorbed through the plywood into the foam. The addition of water will increase the solid thermal conductivity of the foam cell support structures, which will increase the overall thermal conductivity in the foam.

Polystyrene foams are hydrophobic, and thus will not experience significant sorption of moisture. Changes in mass are due to changes in the composition of gases trapped inside the cells [27]. All of the samples had been stored in laboratory for several months before exposure in the environmental chamber. During that time some blowing agent gases would have already diffused out and some ambient air diffused in. Since the material is hydrophobic, sorption of the moisture from the air would not occur as it does with the polyurethane. Any condensation that had occurred on the surface or within the cells of the foam would be removed by exposure to high temperatures. The dryer conditions provide more capacity to evaporate liquid, explaining why a more significant decrease in thermal conductivity is seen when exposed to the lower humidity conditions. No chemical analysis was performed on the polystyrene samples, so the possibility the chamber conditions effecting a chemical change is not addressed here.

Since PUR samples were not tested at the lower temperature settings, temperature effects are not as readily seen. It can be inferred, however, from the data presented in Figure 4, that higher 
temperatures tend to increase the rate of effluence of blowing agent. The slopes of the two environmental chamber samples are steeper than the slope of the conglomerate data of samples at ambient conditions, indicating an increased degradation rate, which is compounded by high levels of humidity. Additionally, the expansion and blistering of the foam can be attributed to exposure to high temperatures. When the foams are heated, the cell structures experience thermal expansion, and so do the gases trapped inside the closed cells. This gaseous expansion drives the deformation of the polyurethane structure of the foam.

\subsubsection{Aerogel blankets}

All three aerogels contain fibers made with PET, which is known to be hygroscopic [28]. Hydrolysis is a large factor in the deterioration of PET as demonstrated by McMahon in his study of the rate of hydrolysis as a function of temperature and $\mathrm{RH}$ [29]. However, in $A A$ and $A B$, the batting is a combination of glass and PET fibers that are encompassed by the hydrophobic aerogel, so there is little uptake in moisture. In AC, since the fibers are more loosely nested with the aerogel particles, the possibility of hygroscopy and hydrolysis is greater. Also, the AC batting consists of bi-component fibers, which would be sensitive to changes in temperature due to a difference in thermal expansion properties of the two components [30]. This explains the significant expansion and decreased thermal performance, while the hydrolysis causes the permanent damage that prevents the fibers from returning to their prior state.

The FTIR analyses that were performed verify a change in chemical groups and structural changes for AC. Figure 11 shows the transmittance spectra of the aerogel blankets subjected to the different environmental conditions. For all three blankets, the transmission peaks in the range of $3800 \mathrm{~cm}-1$ to $3500 \mathrm{~cm}-1$ indicate there is free water and hydroxyl group in the baseline spectrum that disappears after exposure to $65.6^{\circ} \mathrm{C}$ and $30 \% \mathrm{RH}$. Similar behavior also can be seen at $65.6^{\circ} \mathrm{C}$ and $90 \% \mathrm{RH}$ conditions (see Figure 12 and Figure 13). The changes are most apparent in AC, and least apparent in AA. At $65.6^{\circ} \mathrm{C}$ and $90 \% \mathrm{RH}$ the FTIR spectra for AA show the peak $3616 \mathrm{~cm}-1$ in baseline and one week samples.

However, after five weeks the $A A$ also chemically release hydroxyl group that is shown by the absence of the peak $3616 \mathrm{~cm}-1$. With the AC, the FTIR spectrum shows that chemical changes take place during environmental chamber treatment (see Figure 14), which is evidence of hydrolysis taking place.

In order to investigate the potential effects of the aerogel microstructure, micrographs were taken with a scanning electron microscope (SEM) to observe possible physical changes in the blankets. No changes were readily apparent in either of $A B$ or $A A$ (see Figure 15 and Figure 16). Notice the tightly packed aerogel substrate behind the loose surface fibers, which remains intact through week 5 for both $A A$ and $A B$. There is no evidence of a change in the aerogel microstructure, and no significant change in the macrostructure of the composite. A general spreading out of the materials in AC, and possible loss of aerogel particles near the surface, can be seen in Figure 17. This is consistent with the expansion of the material, illustrated by Figure 18. We can clearly see from these images that $A C$ has larger macropores than $A A$ and $A B$, consistent with the overall higher thermal conductivity of $A C$, according to [31].

Despite a lack of major chemical or physical changes apparent in $A A$ and $A B$, these insulation types tend to decrease in thermal performance when exposed to elevated temperature and humidity conditions. The greatest change occurs at $65.6^{\circ} \mathrm{C}$ and $90 \% \mathrm{RH}$ followed by $32.2^{\circ} \mathrm{C}$ and $90 \% \mathrm{RH}$. Relatively little change occurs at $65.6^{\circ} \mathrm{C}$ and $30 \% \mathrm{RH}$. Clearly the relative humidity level plays a more important role than the temperature. In fact, contrary to the results for $A C$, both $A A$ and $A B$ see little change due to temperature. This indicates that the primary cause of degradation of thermal performance results from increased relative humidity within the blanket structure. Upon removal from the environmental chamber and placing the sample into the HFMA, the decreased temperature of the ambient and of the cold side plate caused the blanket materials to drop below the dew point of the internal air. Condensation thus formed on the fibers and aerogel, introducing a new heat transfer material with 
increased heat flow. In some cases, condensation was visible on the upper (cold) plate of the HFMA after testing some of the aerogel blankets, which supports this conclusion. Additionally, it would be difficult to observe this behavior through FTIR or SEM due to the higher surface area to volume ratio of the smaller samples used for those analyses, leading to quicker escape of humidity. This is confirmed by HFMA measurements that were taken of a few samples multiples weeks after being placed back into ambient conditions. The samples that were removed from $65.6^{\circ} \mathrm{C}$ and $30 \% \mathrm{RH}$ tended to further degrade (ambient conditions were typically between $40-50 \% \mathrm{RH}$ ), while samples that were removed from $65.6^{\circ} \mathrm{C}$ and $90 \%$ tended to recover slightly.

In the case where half of the samples of AA exposed to $65.6^{\circ} \mathrm{C}$ and $30 \% \mathrm{RH}$ increased in thermal resistivity by about $2 \%$, while half decreased by about $2 \%$, it is suspected that differences in ambient temperature were enough to span the resulting internal humidity levels within the blankets during HFMA tests. If the ambient conditions are drier, condensation within the insulation is less likely, leading to a slight increase in thermal resistivity. If the ambient conditions are more humid, condensation within the insulation is more likely, leading to a slight decrease in thermal resistivity. Ultimately little change was seen overall when exposed to these hot/dry conditions.

The changes that occur in $A C$ are driven more by temperature than humidity level. Its expansion is evidence of some amount of thermal expansion and moisture sorption into the fibers. The added heat increases the rate of hydrolysis and causes permanent change. There is an abrupt initial increase in thermal conductivity; however, it doesn't experience significant change during the remaining aging. This indicates that the change occurs initially but then reaches equilibrium with the moisture levels.

Interestingly, although the value of thermal conductivity increases in AC, the heat flux decreases. The increase in thermal conductivity is driven by volume expansion of the material, rather than an increase in heat flow through the material (see Figure 10). Heat flow is determined by Fourier's law as $q=-\mathrm{k}(\Delta \mathrm{T} / \mathrm{d})$, where $\mathrm{k}$ is thermal conductivity, $q$ is heat flux, $\Delta \mathrm{T}$ is the change in temperature across the material and $d$ is the thickness of the material. Accordingly, an increase in thermal conductivity, in combination with an increase in thickness while keeping the change in temperature constant, can yield a decrease in heat flux when the change in thickness is greater than the change in thermal conductivity, as is the case here.

It should be noted that $A C$, similar to $A A$ and $A B$, is less likely to be affected by humidity levels within the insulation. By nesting aerogel particles inside the batting, rather than forming a monolith around them, significantly more aerogel surface is exposed to ambient air. This causes an increase in diffusion, allowing $A C$ to reach equilibrium much quicker than $A A$ and $A B$. The samples of $A C$ that were measured after several weeks back in ambient conditions did not show a consistent pattern, which indicates much quicker diffusion time scale than for the $A A$ and $A B$ samples.

\section{Conclusions ${ }^{3}$}

No apparent humidity effects were discovered for XPS foam. The high heat seems to cause some small amounts of change and even decreases the thermal conductivity of the foams, due to exchange of higher and lower thermal conductivity gases in and out of the material. Humidity plays an important role in the initial change in thermal conductivity of the spray PUR foam and Aerogel blankets AA and AB. All three experience gradual degradation after an initial change in thermal conductivity. In the PUR foam this is due to loss of blowing agent and sorption of moisture. In the aerogel blankets it is due to diffusion of higher humidity air into the aerogel, which then leads to condensation. Aerogel blanket AC also sees an initial change in thermal conductivity with a corresponding change in thickness. This change in thickness is effected by temperature and humidity levels, which also drive a chemical change (hydrolysis) in the fibers. In general the PUR foam on plywood typically changes in thermal performance by less than $10 \%$ and the aerogel blankets typically change by less than $5 \%$. 


\section{Acknowledgements}

2 The authors would like to acknowledge the financial support of the United States Army and 3 Department of Defense.

4

${ }^{1}$ Distribution Statement A: Approved for public release; distribution is unlimited.

${ }^{2}$ Citation of trade names does not constitute an official endorsement or approval of the use of such commercial products. All product names and trademarks cited are the property of their respective owners.

${ }^{3}$ Results are based on limited studies performed with a narrow scope and are not intended to be an authoritative evaluation of any products. The findings of this report are not to be construed as an official Department of the Army position unless so designated by other authorized documents. 


\section{References}

[1] Lawrence Livermore National Laboratory (LLNL). (2013). Estimated U.S. Energy Use in 2012: 95.1 Quads [Online]. Available: https://flowcharts.Ilnl.gov/energy.html\#2012

[2] U.S. Energy Information Administration (U.S. EIA). (March 2013). Residential Energy Consumption Survey (RECS), Overview [Online]. Available: http://www.eia.gov/consumption/residential/index.cfm

[3] U.S. Energy Information Administration (U.S. EIA). (2008). Commercial Buildings Energy Consumption Survey (CBECS), Overview of Commercial Buildings, 2003 [Online]. Available: http://www.eia.gov/consumption/commercial/data/archive/cbecs/cbecs2003/overview.pdf

[4] S. S. Kistler, "Coherent expanded aerogels and jellies," Nature, vol. 127, pp. 741, 1931.

[5] J. Fricke, "AEROGELS," Sci. Am., vol. 258, pp. 92-97, 1988.

[6] M. Schmidt and F. Schwertfeger, "Applications for silica aerogel products," J. Non Cryst. Solids, vol. 225, pp. 364368, 1998.

[7] M. Bouquerel, T. Duforestel, D. Baillis and G. Rusaouen, "Heat transfer modeling in vacuum insulation panels containing nanoporous silicas - A review," Energy Build., vol. 54, pp. 320-336, 2012.

[8] L. D. Stephenson, A. Heffron, B. Mehnert and D. Lawrence, "Laboratory testing predicts long-term degradation of insulating materials," Mater. Perform., vol. 52, pp. 37-41, 2013.

[9] S. Trpevski, "Technical improvement of housing envelopes in the F.Y.R. of Macedonia," Research in Architectural Engineering Series, vol. 5, pp. 83-94, 2007.

[10] Z. Zhu, J. H. Zong, C. B. Park and M. Choudhary, "Effect of loss of blowing agents on thermal insulation properties of polystyrene foams," Journal of Heat Transfer, vol. 131, pp. 1-8, 2009.

[11] Honeywell, "Soltice(TM) LBA [Safety Data Sheet]," Jan 6, 2014. Available: http://msdsresource.honeywell.com/ehswww/hon/result/report.jsp?P_LANGU=E\&P_SYS=1\&P_SSN=51465\&P_REP=00000000 $00000000001 \& P_{-}$RES $=15146$

[12] Dow, "STYROFOAM(TM) 2.00 x 24 Inch Panel Core 20 - XNERGY(TM) [Safety Data Sheet]," Oct. 29, 2009. Available: http://www.dryvit.com/fileshare/doc/us/msds/msds_191.pdf

[13] A. Parasin V. and N. J. Nagy, "Effect of spray-applied polyurethane foam insulation on the racking load of a plywood sheathed wood frame wall," Council of Forest Industries of B.C., Canada, Tech. Rep. 91.1, 1991.

[14] Honeywell, "Enovate ${ }^{\circledR} 245 f a$ [Safety Data Sheet]," Apr 3, 2013. Available: http://msdsresource.honeywell.com/ehswww/hon/result/wait.jsp?P_LANGU=E\&P_SYS=1\&P_SSN=51468\&P_REP=0000000000 0000000001\&P_RES=15148\&P_SPEC=R

[15] G. Wei, Y. Liu, X. Zhang, F. Yu and X. Du, "Thermal conductivities study on silica aerogel and its composite insulation materials," Int. J. Heat Mass Transfer, vol. 54, pp. 2355-2366, 2011.

[16] M. Ramamurthi and S. Ramamurthi, "Aerogel matrix composites," U.S. Patent 5306 555, Apr. $26,1994$.

[17] D. Frank, A. Zimmermann and F. Thonnessen, "Fiber web/aerogel composite material comprising bicomponent fibers, production thereof and use thereof," U.S. Patent 5786 059, July 28, 1998.

[18] Aspen Aerogels, "Spaceloft ${ }^{\circledR}$ Silica Aerogel materials [Safety Data Sheet]," Feb. 9, 2011. Available: http://www.aerogel.com/products/pdf/Spaceloft_MSDS.pdf

[19] Acoustiblok Inc, "Thermablok Thermal Acoustic Isolation Strips [Safety Data Sheet]," Jan. 7, 2009. Available: http://www.thermablok.com/pdf/Thermablok_msds_20090318.pdf

[20] Cabot Corporation, "Aerogel Thermal Wrap [Safety Data Sheet]," Mar. 4, 2013. Available: http://www.cabotcorp.com/wcm/msds/en-us/AE/NGBL-NA-EN.pdf

[21] J. Zhao, Y. Duan, X. Wang, B. Wang, "Radiative properties and heat transfer characteristics of fiber-loaded silica aerogel composites for thermal insulation," Int. J. Heat and Mass Trans., vol. 55, pp. 5196-5204, 2012.

[22] T. Xie, Y. He, Z. Hu, "Theoretical study on thermal conductivities of silica aerogel composite insulating material," Int. J. Heat and Mass Trans., vol. 58, pp. 540-552, 2013.

[23] A. Hoseini, A. Malekian, M. Bahrami, "Deformation and thermal resistance study of aerogel blanket insulation material under uniaxial compression," Energy Build., vol. 130, pp. 228-237, 2016.

[24] A.F. Mills, "Modes of Heat Transfer," in Heat Transfer, $2^{\text {nd }}$ ed. Upper Saddle River, New Jersey: Prentice Hall, 1999, ch. 1, sec. 3, pp.7-11

[25] J. R. Booth, R. S. Graves and D. W. Yarbrough, "Aging of thin-slices of PIR foams manufactured with alternative blowing agents," Journal of Thermal Insulation and Building Envelopes, vol. 19, pp. 118-131, 1995.

[26] I. M. Marrucho, F. Santos, N. S. Oliveira and R. Dohrn, "Aging of rigid polyurethane foams: Thermal conductivity of N 2 and cyclopentane gas mixtures," Journal of Cellular Plastics, vol. 41, pp. 207-224, 2005.

[27] R. R. Zarr and T. Nguyen, "Effects of humidity and elevated temperature on the density and thermal conductivity of a rigid polyisocyanurate foam co-blown with $\mathrm{CCl} 3 \mathrm{~F}$ and $\mathrm{CO} 2$, " Journal of Thermal Insulation and Building Envelopes, vol. 17, pp. 330-350, 1994. 
[28] S. A. Jabarin and E. A. Lofgren, "Effects of water absorption on physical properties and degree of molecular orientation of poly (ethylene terephthalate)," Polymer Engineering \& Science, vol. 26, pp. 620-625, 1986.

[29] W. Mcmahon, H. A. Birdsall, G. R. Johnson and C. T. Camilli, "Degradation studies of polyethylene terephthalate," J. Chem. Eng. Data, vol. 4, pp. 57-79, 1959.

[30] J. Kaufmann, "Thermally responsive fiber concept leads to developments in adaptive insulation," International Fiber Journal, vol. 20, no. 2, pp. 44-45, 2005.

[31] G. Wei, L. Wang, C. Xu, X. Du, Y. Yang, "Thermal conductivity investigations of granular and powdered silica aerogels at different temperatures and pressures," Energy Build., vol. 118, pp. 226-231, 2016. 
Table 1 Summary of insulating materials tested

\begin{tabular}{|l|l|l|l|}
\hline Label & Type of insulation & Other components & Mfg. Process \\
\hline XPA & Polystyrene foam & trans-1,3,3,3-Tetrafluoroprop-1-ene blowing agent & Extruded \\
\hline XPB & Polystyrene foam & $\begin{array}{l}\text { 1-Chloro-1,1-difluoroethane and 1,1,1,2- } \\
\text { Tetrafluoroethane blowing agent }\end{array}$ & Extruded \\
\hline PUR & $\begin{array}{l}\text { Polyurethane foam } \\
\text { + plywood }\end{array}$ & $\begin{array}{l}\text { 1,1,1,3,3-Pentafluoropropane blowing agent, plywood } \\
\text { substrate }\end{array}$ & Sprayed \\
\hline AA & Aerogel composite & Calcium Silicate dopant, glass and PET fibers & Molded \\
\hline AB & Aerogel composite & Glass and PET fibers & Molded \\
\hline AC & Aerogel composite & $\begin{array}{l}\text { Bicomponent fibers with PET core and copolyolefin } \\
\text { sheath }\end{array}$ & $\begin{array}{l}\text { Nested and } \\
\text { fused }\end{array}$ \\
\hline
\end{tabular}

Table 2 Comparison of calculated vs. actual removal of plywood thermal effects from PUR/plywood composite

\begin{tabular}{|c|c|}
\hline \multicolumn{2}{|c|}{ Composite PUR and Plywood } \\
R value/in. calculations, $\mathrm{ft}^{2} \cdot{ }^{\circ} \mathrm{F} \cdot \mathrm{hr} / \mathrm{BTU} \cdot \mathrm{in}$ \\
(resistivity, $\mathrm{K} \cdot \mathrm{m} / \mathrm{W}$ ) \\
\hline Composite & 2.98 \\
& $(0.430)$ \\
\hline Plywood after removal & 1.43 \\
& $(\mathbf{0 . 2 0 6 )}$ \\
\hline PUR & 4.17 \\
plywood physically removed & $(0.601)$ \\
\hline PUR & 4.13 \\
\hline
\end{tabular}




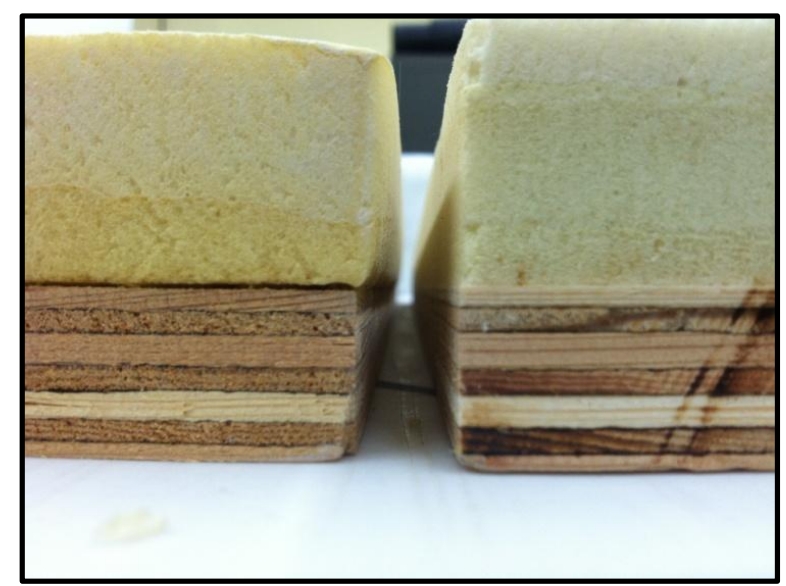

(a)

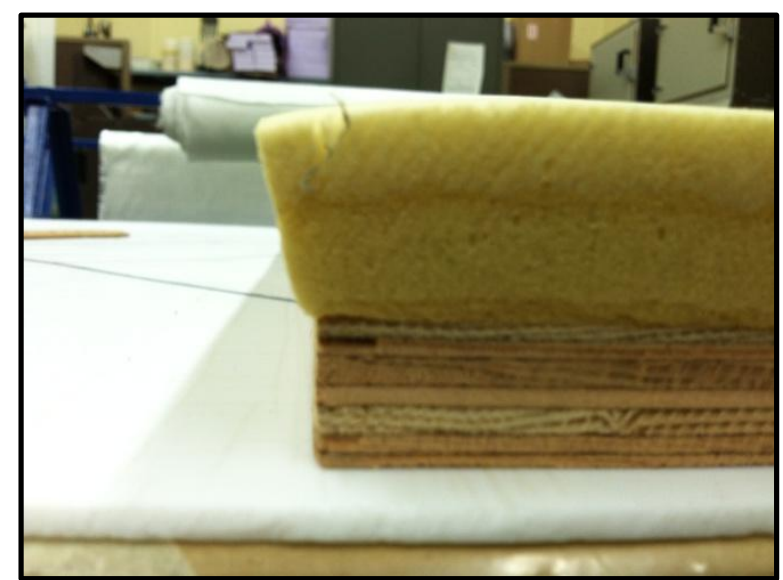

(b)

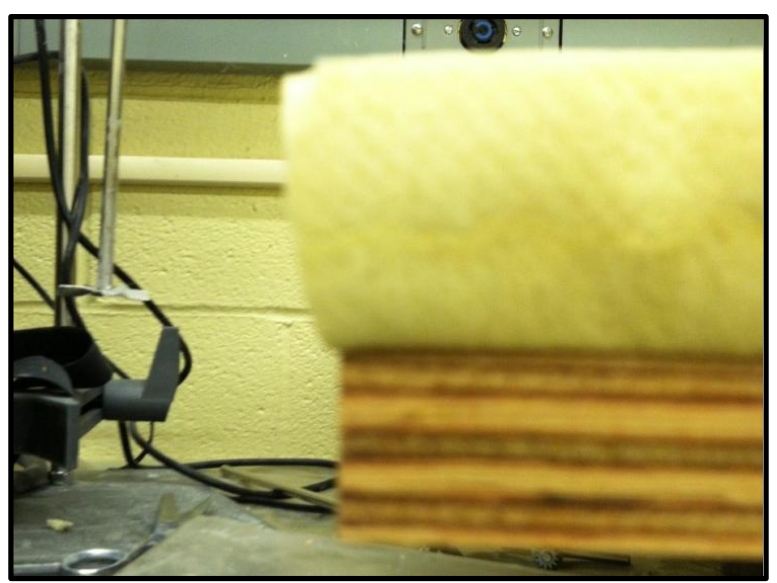

(c)

Figure 1 PUR composite samples exposed at (a) $65.6^{\circ} \mathrm{C}$ and $30 \% \mathrm{RH}$ on the left, no exposure on the right, (b) $65.6{ }^{\circ} \mathrm{C}$ and $60 \% \mathrm{RH}$ and (c) $65.6^{\circ} \mathrm{C}$ and $90 \% \mathrm{RH}$

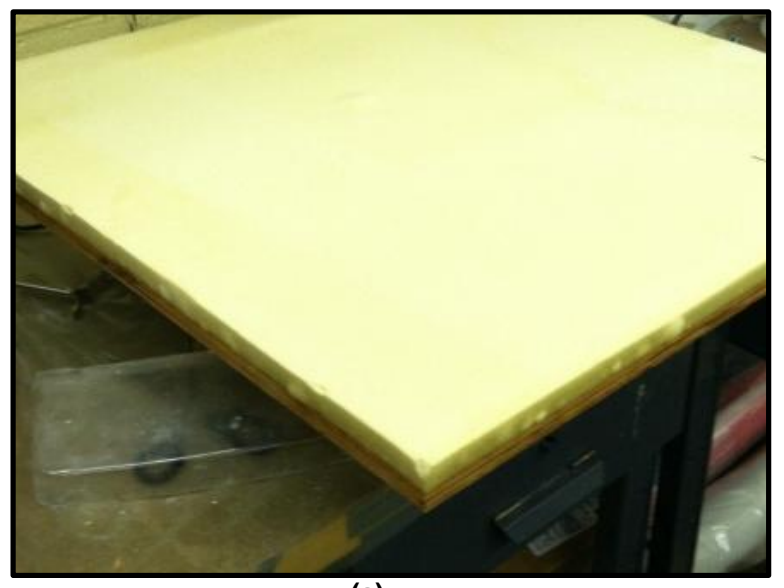

(a)

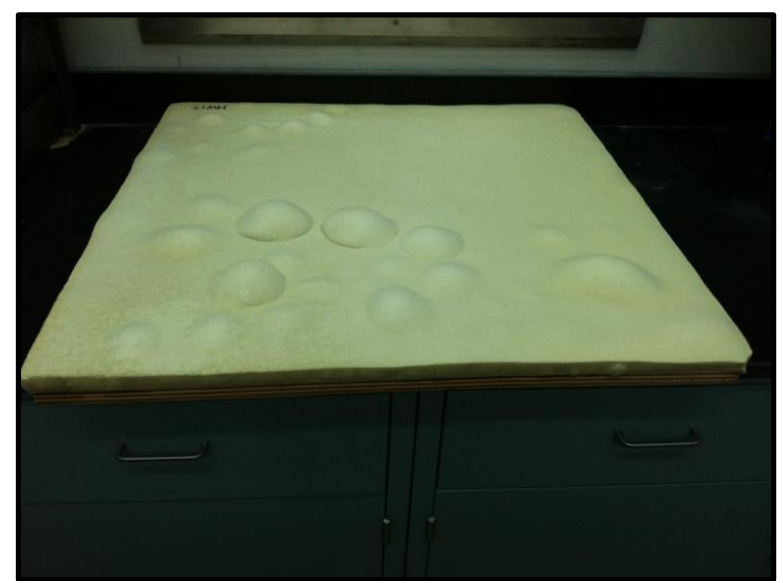

(b)

Figure 2 (a) Typical blistering shown on edges of a PUR sample, (b) Severe blistering shown on top of a PUR sample 

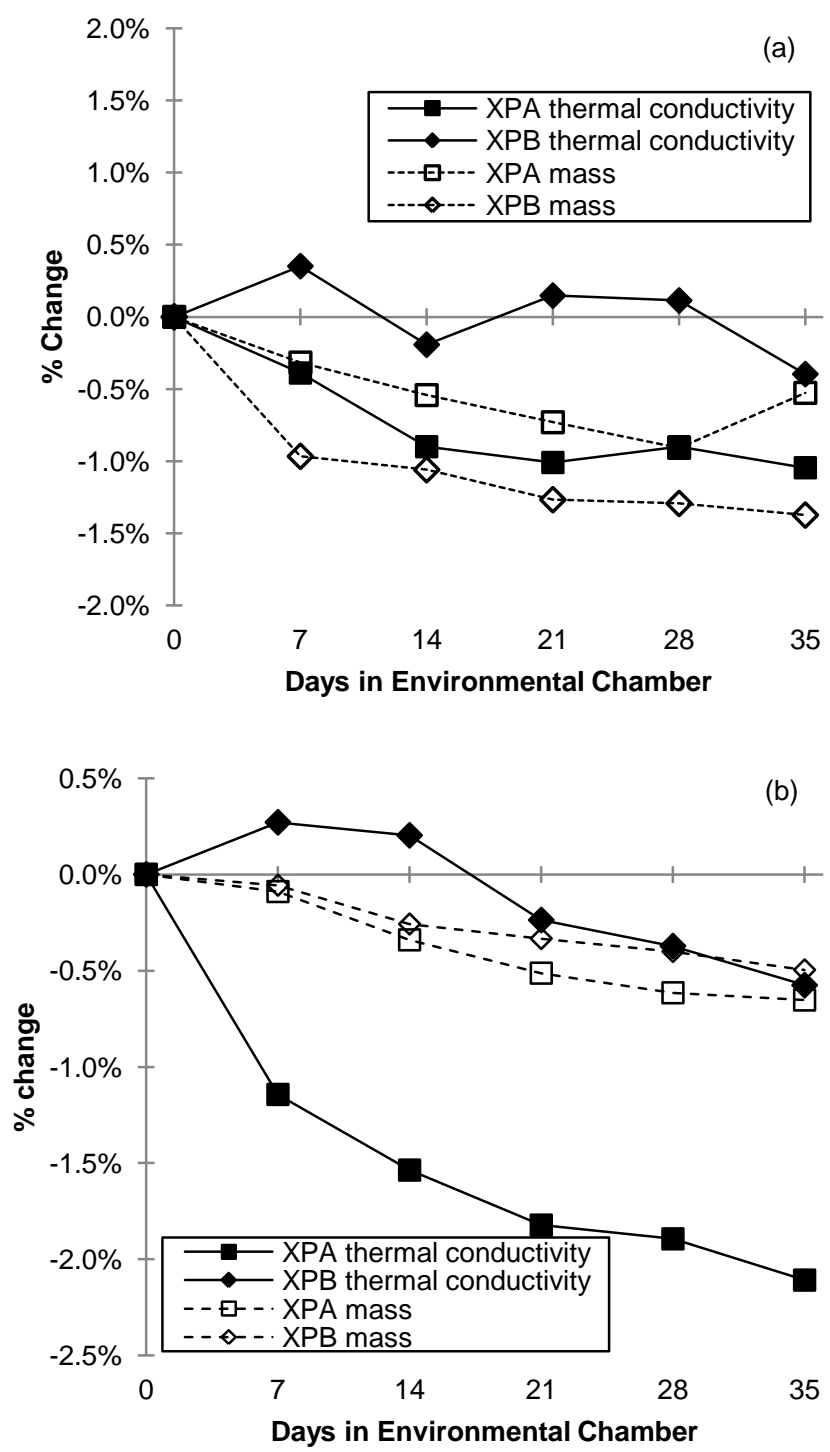

Figure 3 Thermal conductivity and moisture change in both XPS types at $65.6{ }^{\circ} \mathrm{C}$ and (a) $90 \% \mathrm{RH}$, (b) $60 \% \mathrm{RH}$ 


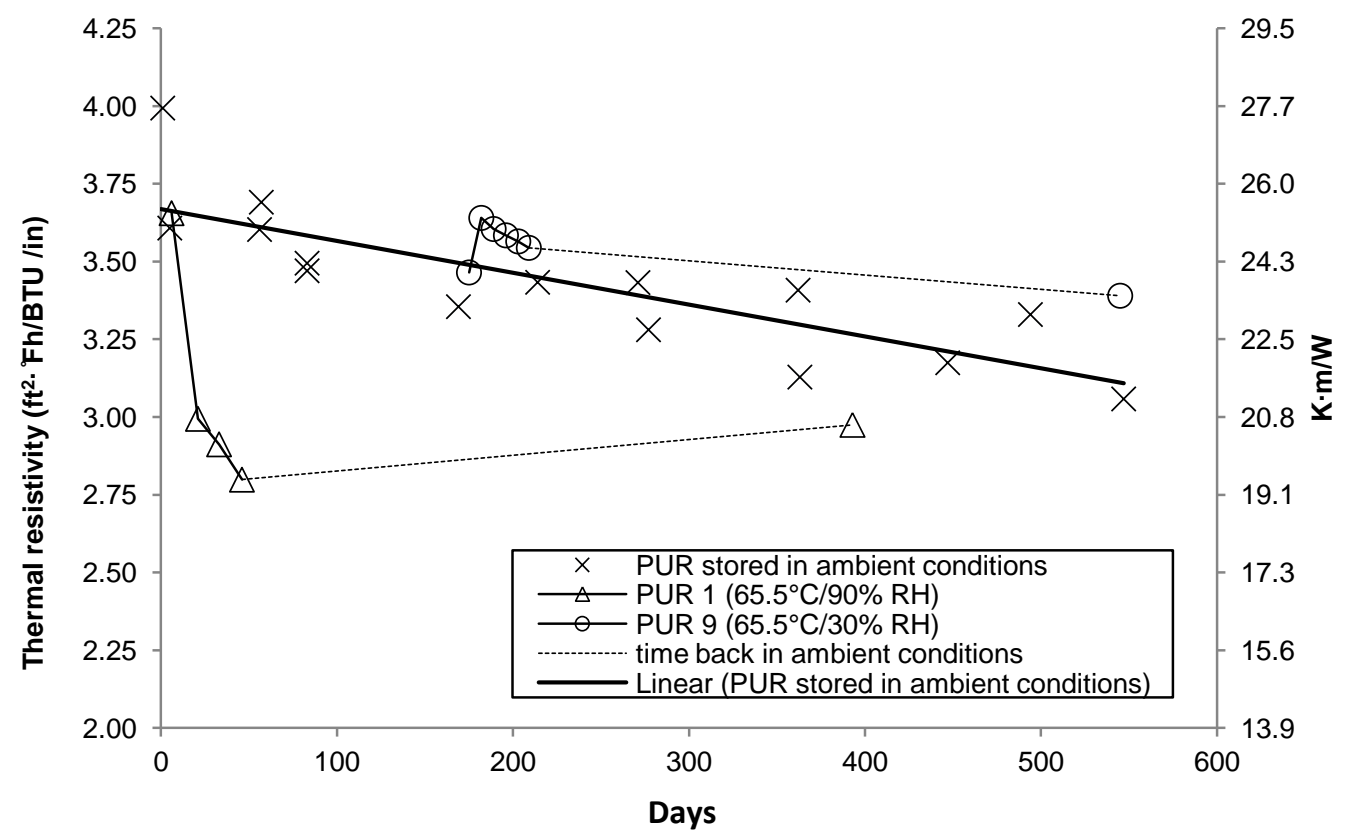

Figure 4 Change in baseline conditions of PUR composites over time, compared to selected aged samples 

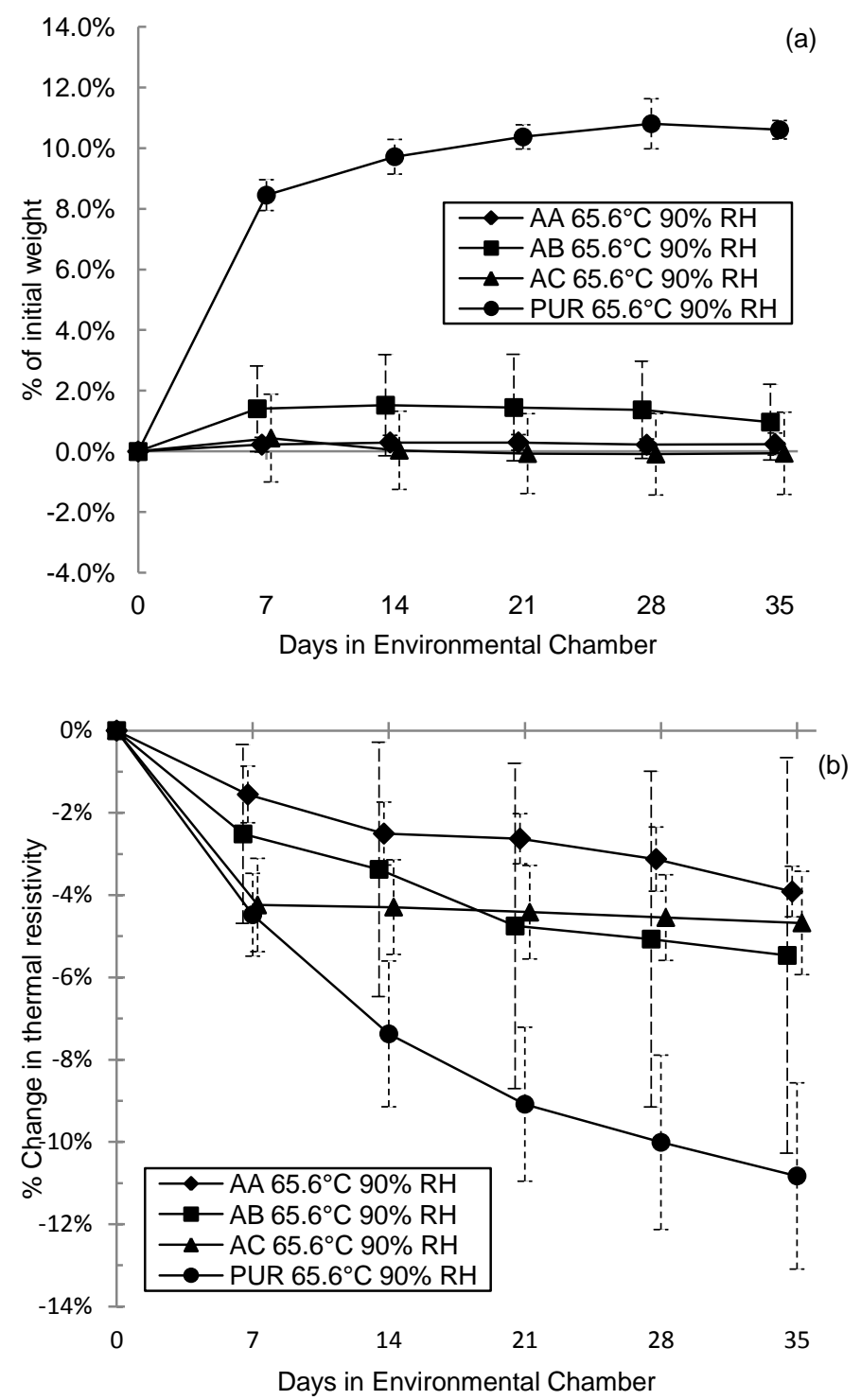

Figure $565.6^{\circ} \mathrm{C}$ and $90 \% \mathrm{RH}$ results for \%change in (a) mass and (b) thermal resistivity 

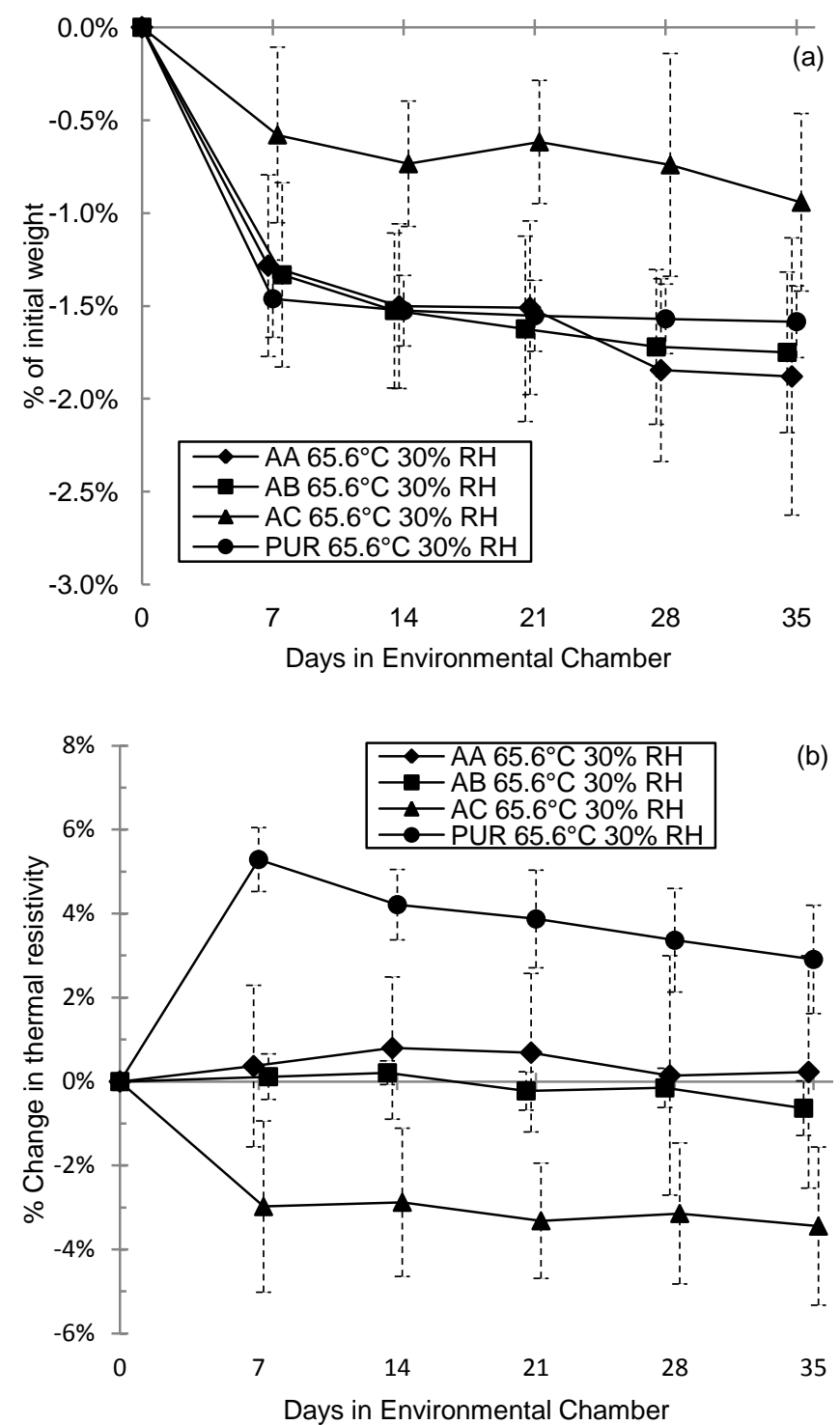

Figure $665.6{ }^{\circ} \mathrm{C}$ and $30 \% \mathrm{RH}$ results for \%change in (a) mass and (b) thermal resistivity 

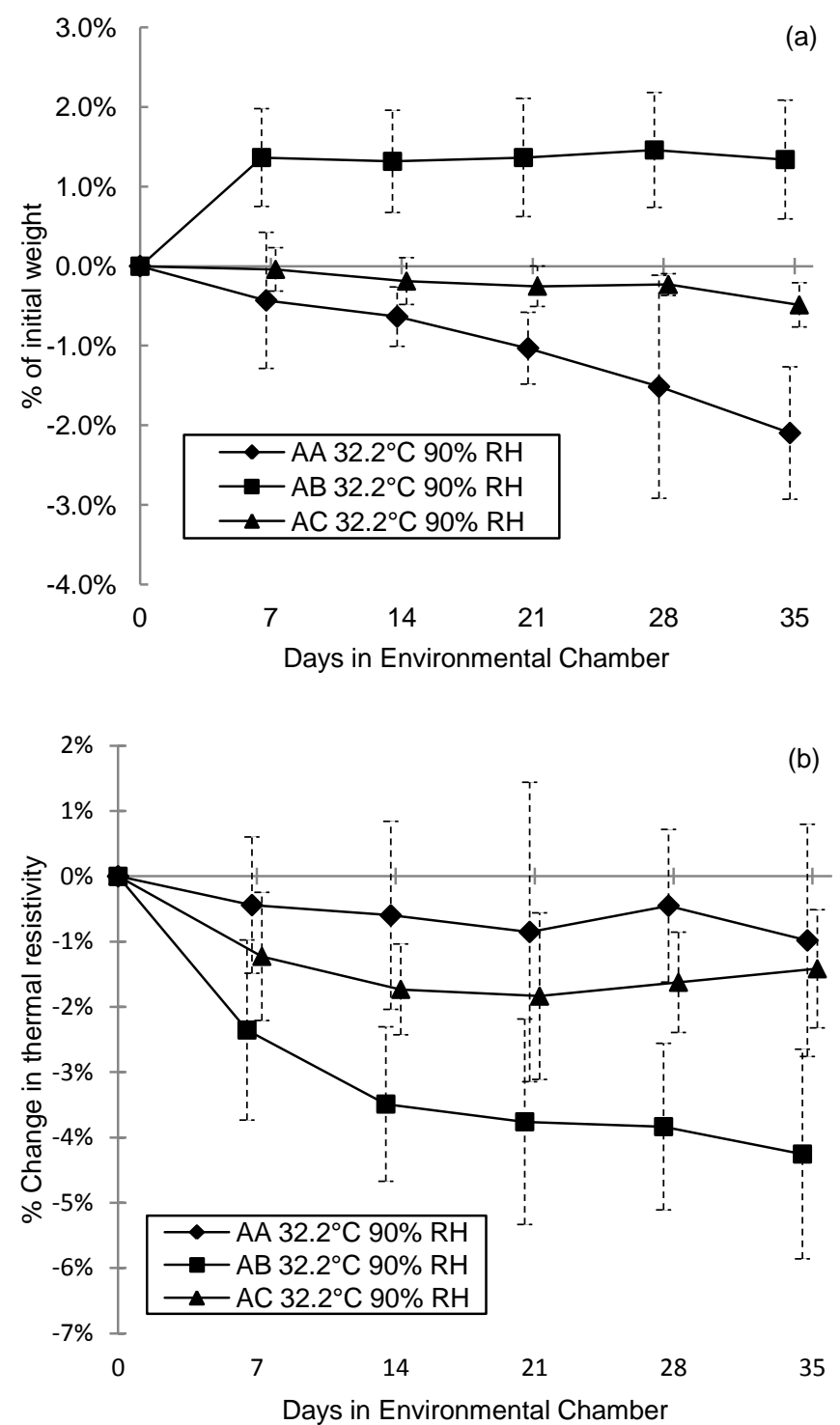

Figure $732.2{ }^{\circ} \mathrm{C}$ and $90 \% \mathrm{RH}$ results for \%change in (a) mass and (b) thermal resistivity 


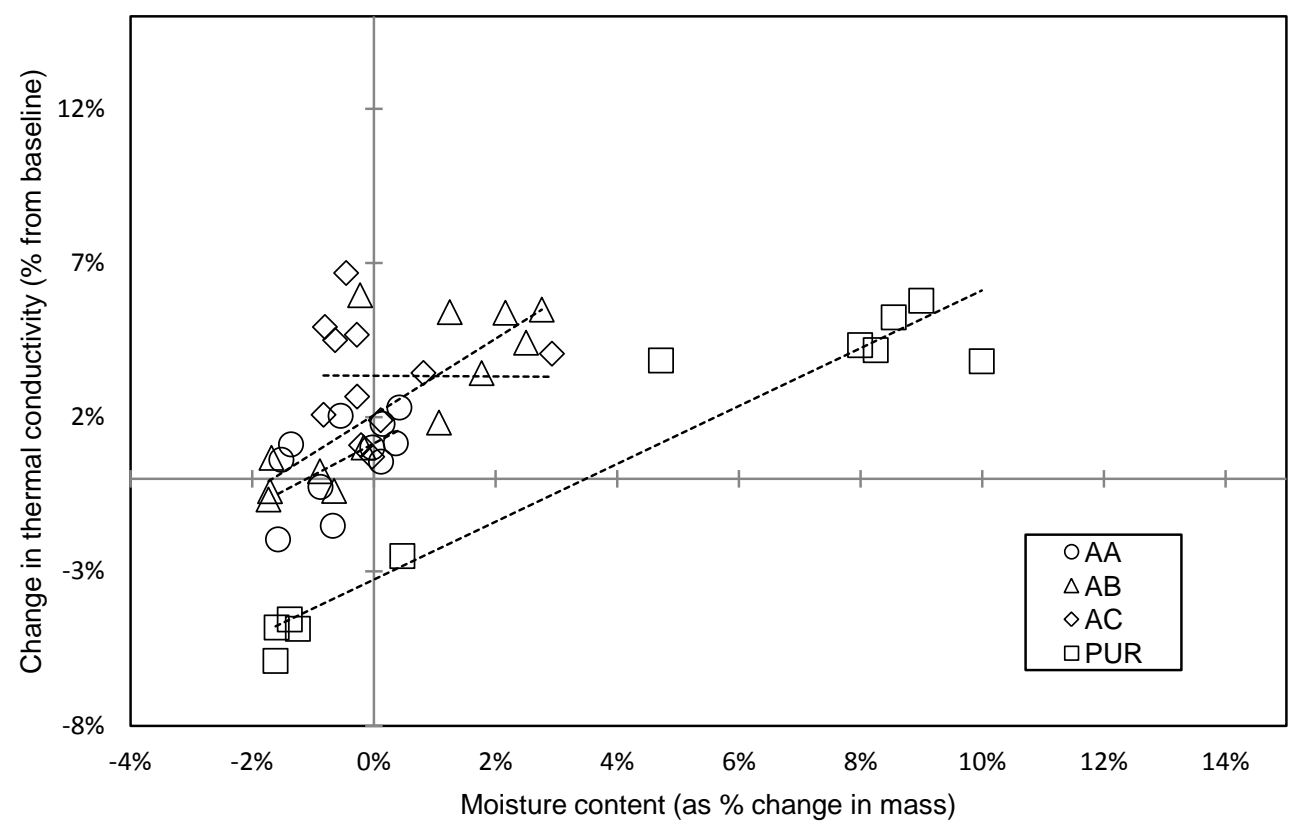

Figure 8 (top) Showing relationship of thermal conductivity vs. moisture content for aerogels and PUR after one week of exposure, with corresponding linear trend lines. General trend of conductivity depending on moisture is apparent for all except AC. Dashed lines are for visual clarity of groups of data.

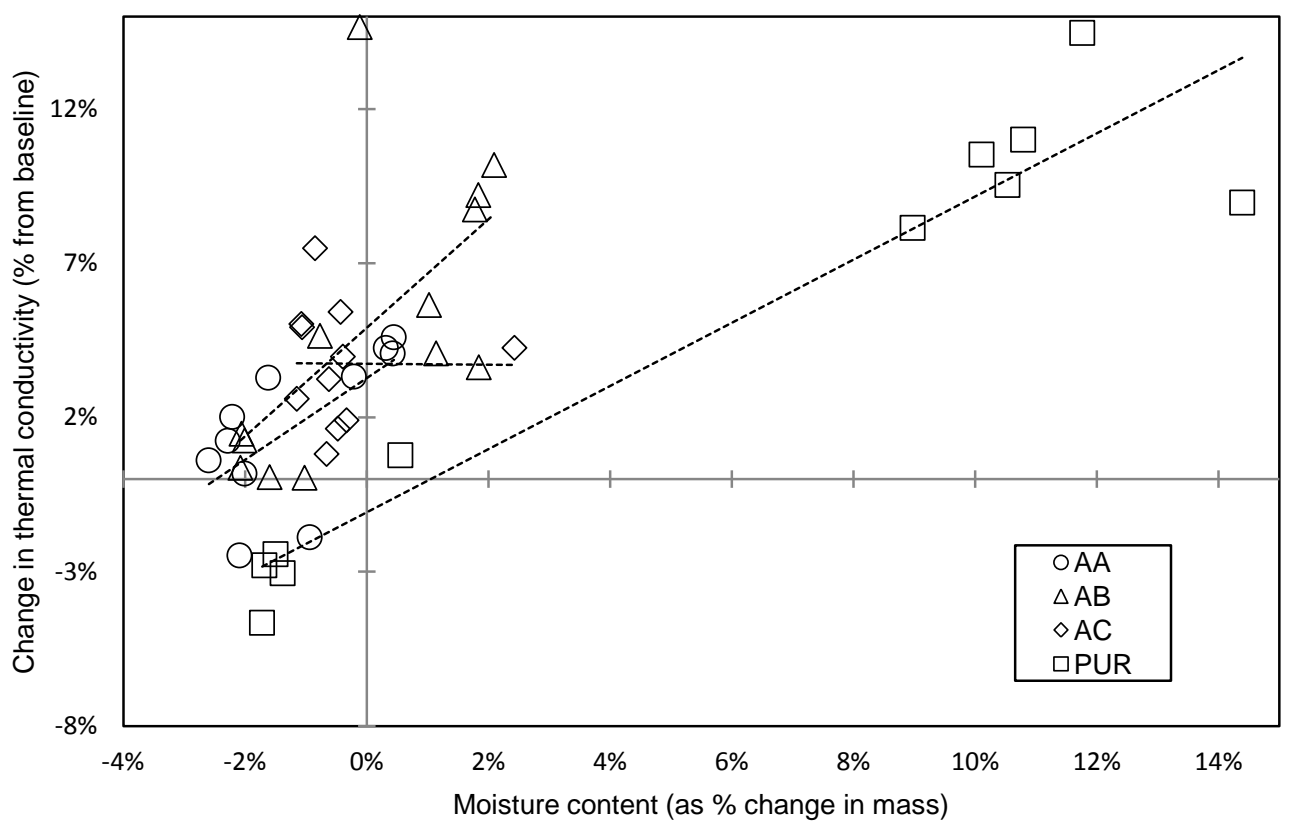

Figure 9 same as Figure 8 but at 5 weeks (4 weeks for PUR). Dashed lines are for visual clarity of groups of data. 

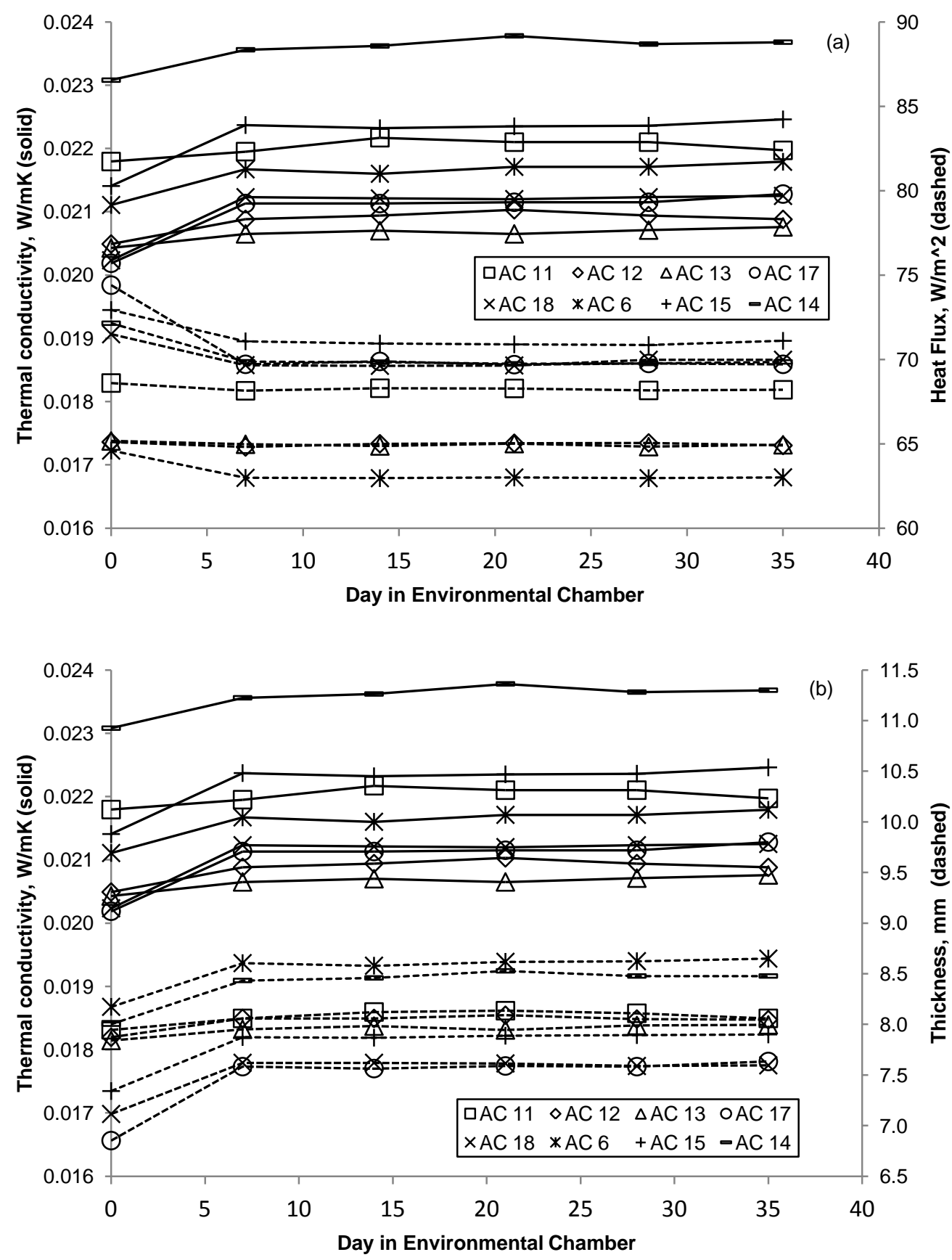

Figure 10 Comparison of changes in (a) thermal conductivity and heat flux and (b) thermal conductivity and thickness for several AC samples 

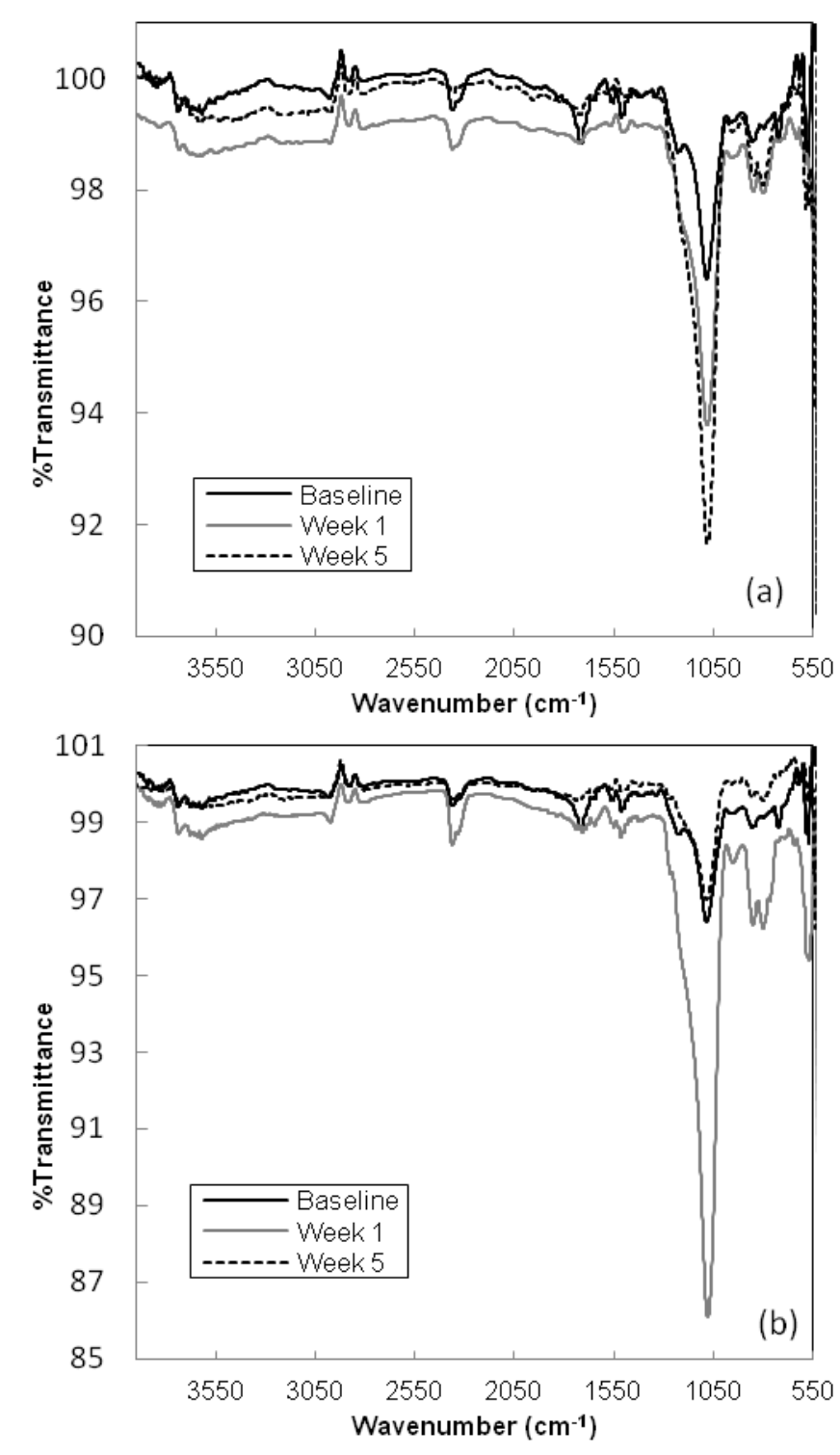

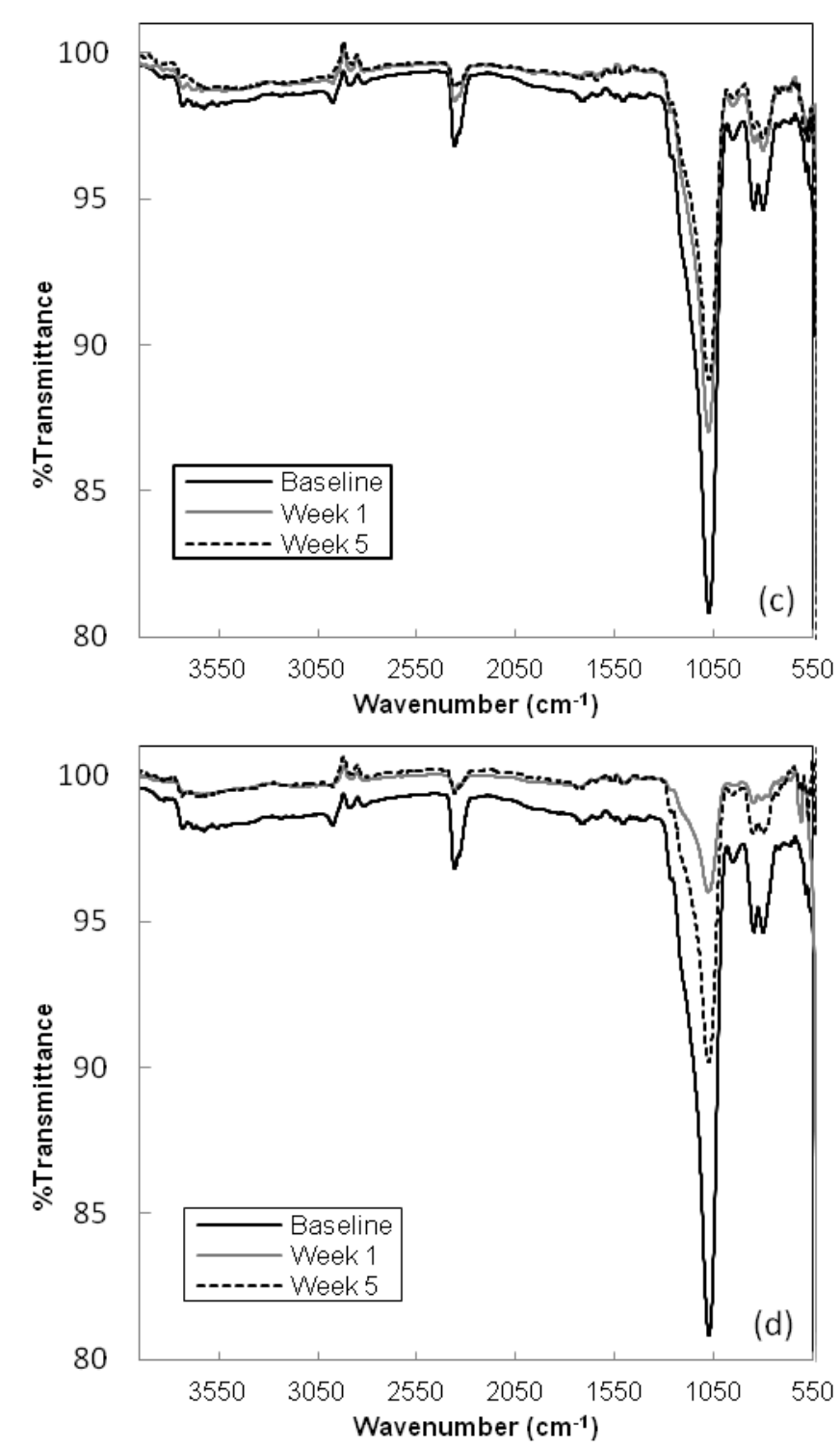

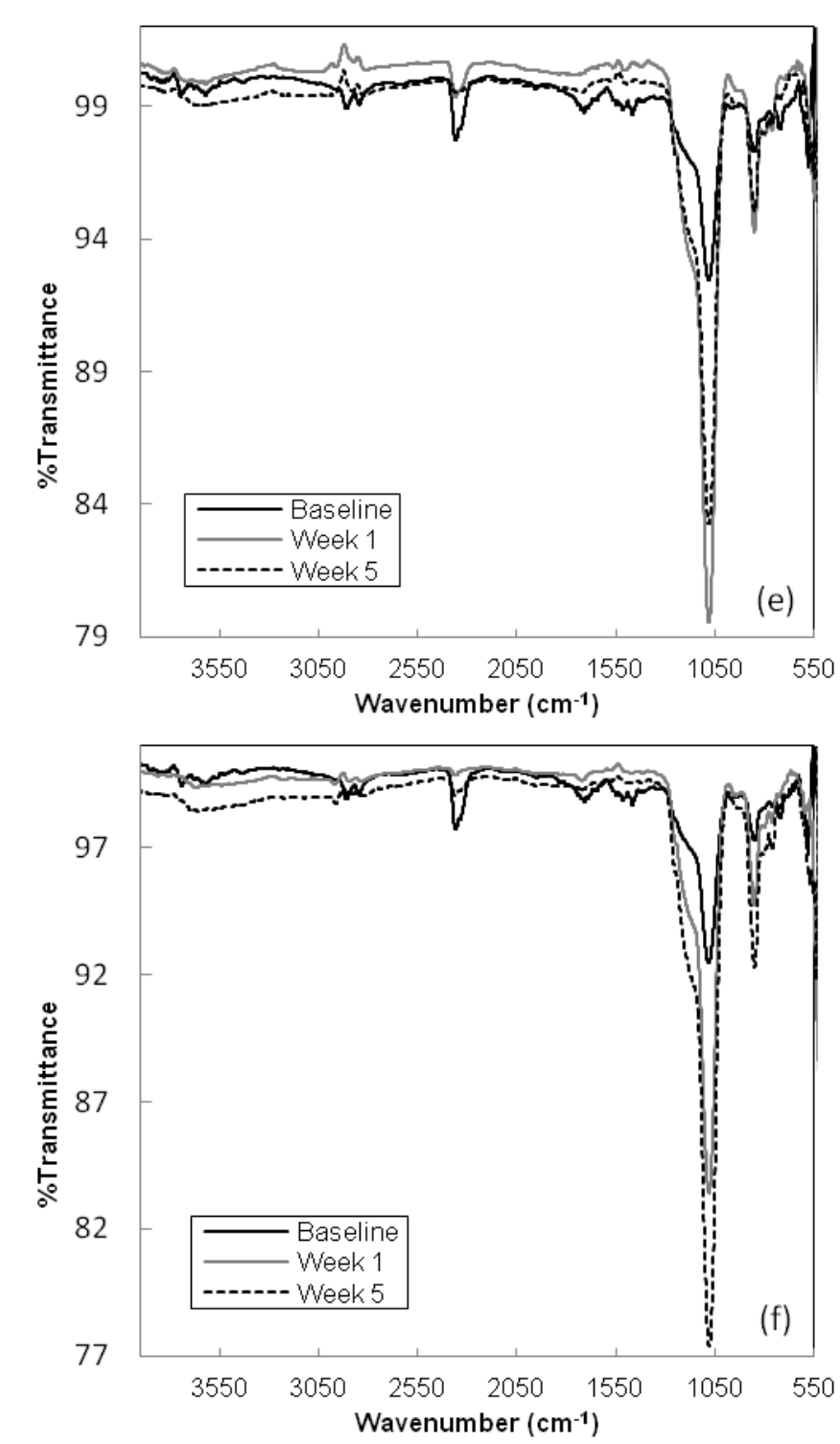

Figure $11 \mathrm{FTIR}$ transmittance spectra of aerogel blankets subjected to environmental conditions. (a) AA at $65.6{ }^{\circ} \mathrm{C}$ and $90 \% \mathrm{RH}$, (b) AA at $65.6^{\circ} \mathrm{C}$ and $30 \% \mathrm{RH}$, (c) AB at $65.6^{\circ} \mathrm{C}$ and $90 \% \mathrm{RH}$, (d) AB at $65.6^{\circ} \mathrm{C}$ and $30 \% \mathrm{RH}$, (e) AC at $65.6^{\circ} \mathrm{C}$ and $90 \% \mathrm{RH}$, (f) $\mathrm{AC}$ at $65.6^{\circ} \mathrm{C}$ and $30 \% \mathrm{RH}$ 


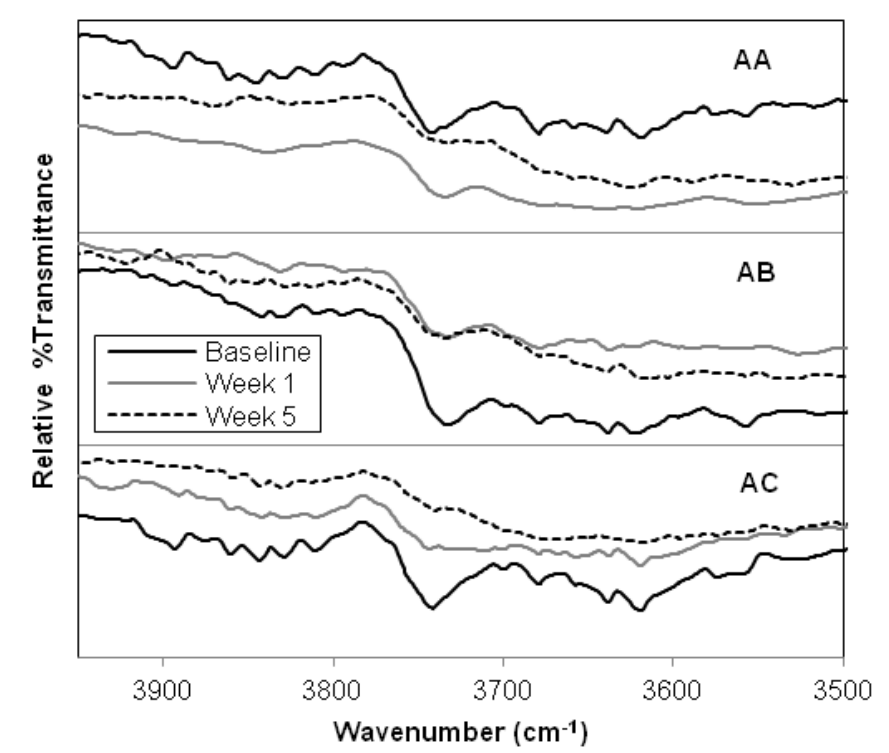

Figure 12 Detail of FTIR overlays of all three aerogel blankets at $65.6^{\circ} \mathrm{C}$ and $90 \% \mathrm{RH}$ showing changes in free moisture

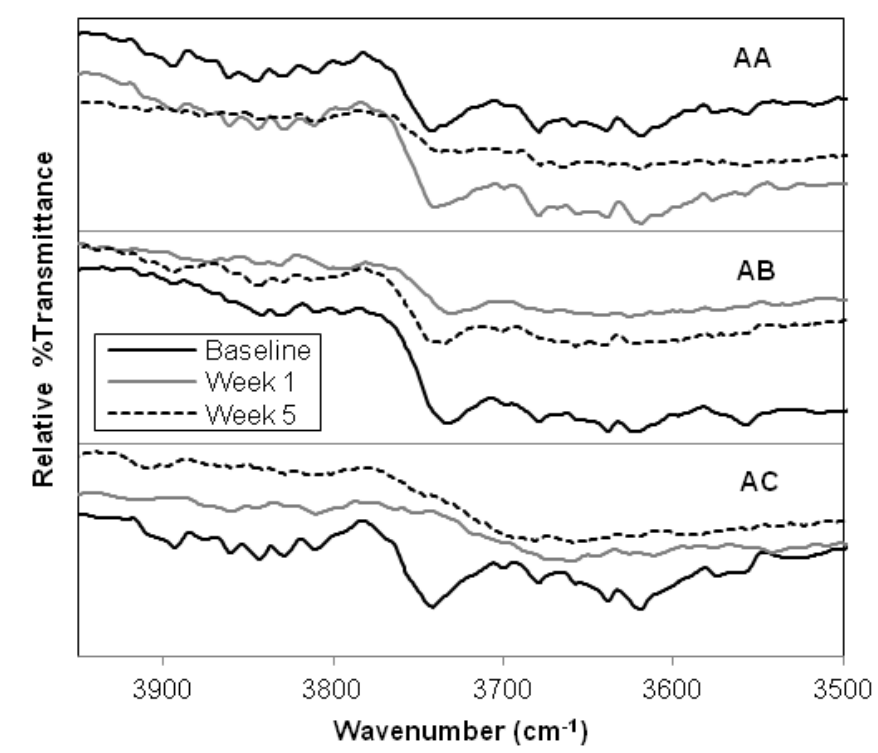

Figure 13 Detail of FTIR overlays of all three aerogel blankets at $65.6^{\circ} \mathrm{C}$ and $30 \% \mathrm{RH}$ showing changes in free moisture 


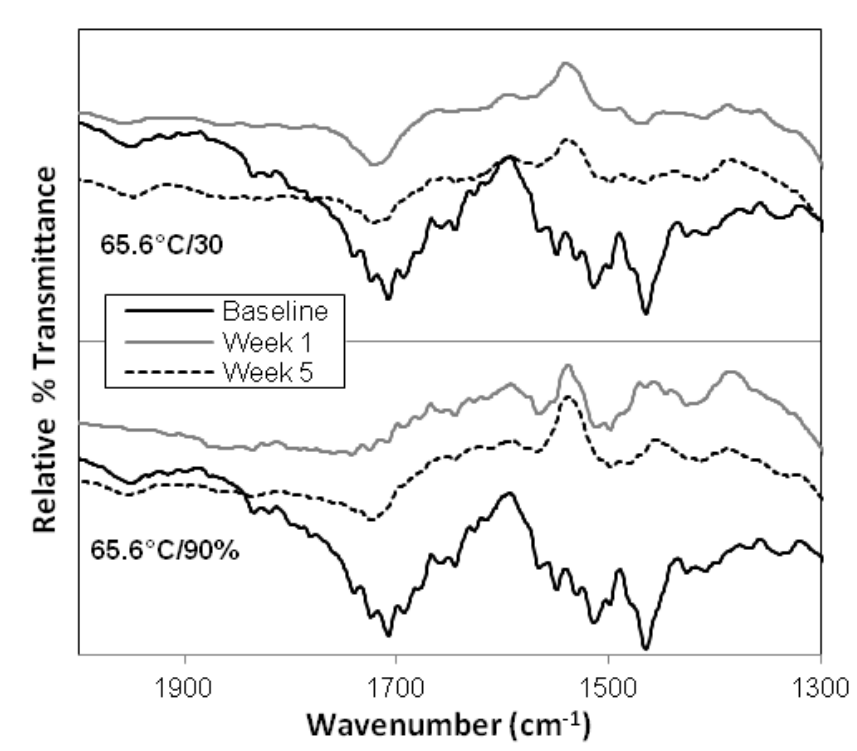

Figure 14 Detail of FTIR overlays of AC at both $90 \% \mathrm{RH}$ and $30 \% \mathrm{RH}$ at $65.6^{\circ} \mathrm{C}$ indicating structural changes

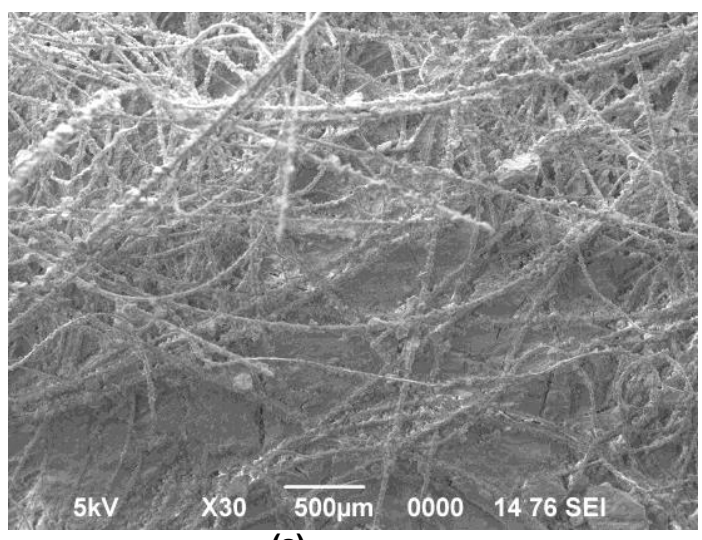

(a)

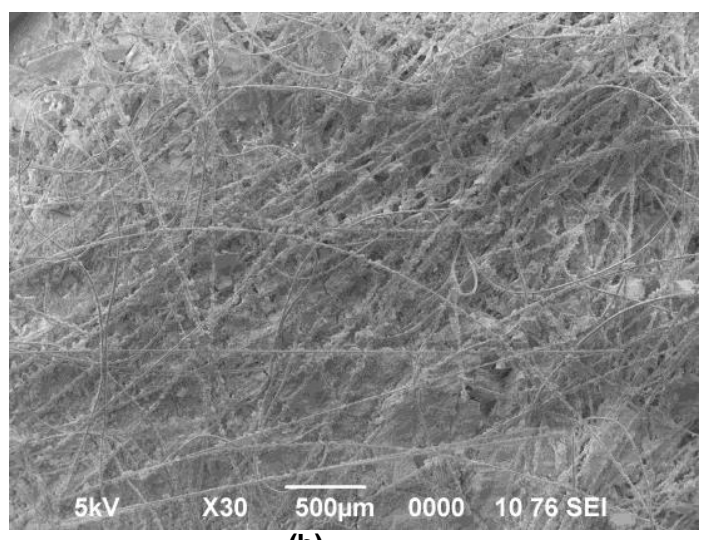

(b)

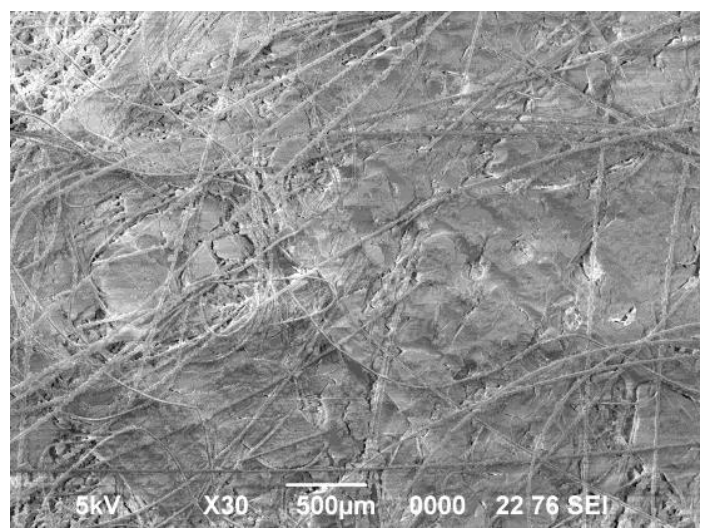

(c)

Figure 15 SEM micrographs of AA aged at $65.6^{\circ} \mathrm{C}$ and $90 \% \mathrm{RH}$ for (a) 0 time, (b) 1 week, (c) 5 weeks 


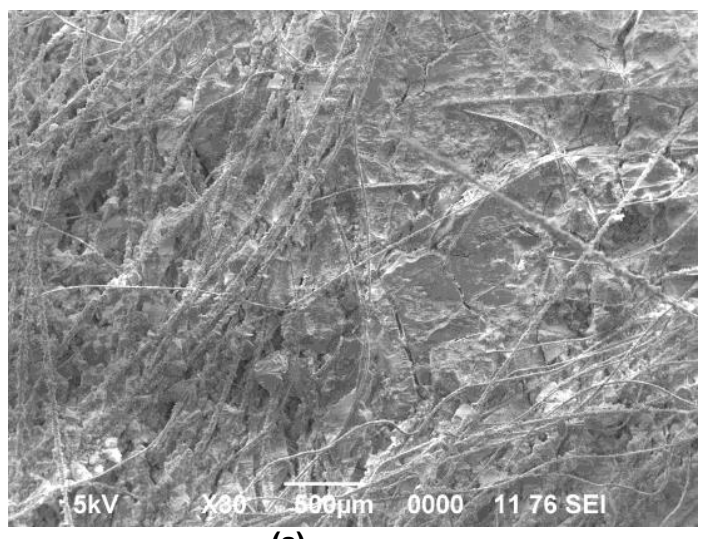

(a)

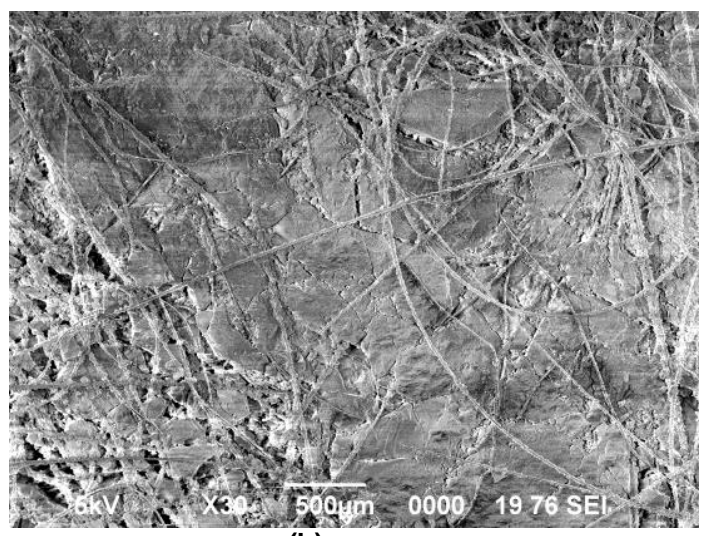

(b)

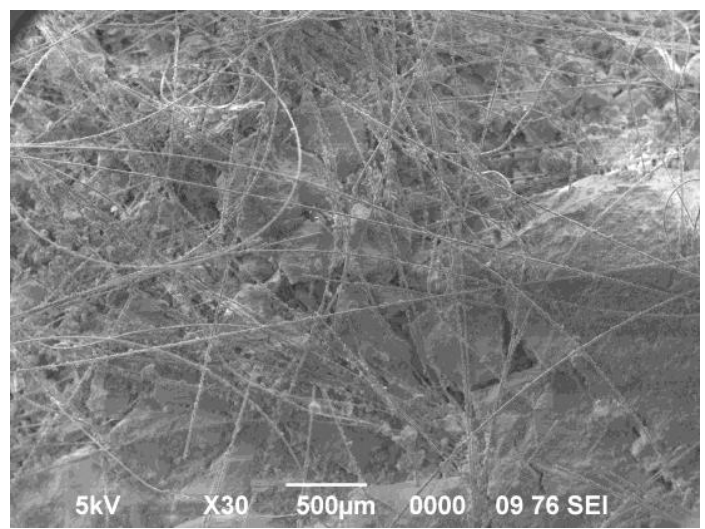

(c)

Figure 16 SEM micrographs of $A B$ aged at $65.6{ }^{\circ} \mathrm{C}$ and $90 \% R H$ for (a) 0 time, (b) 1 week, (c) 5 weeks

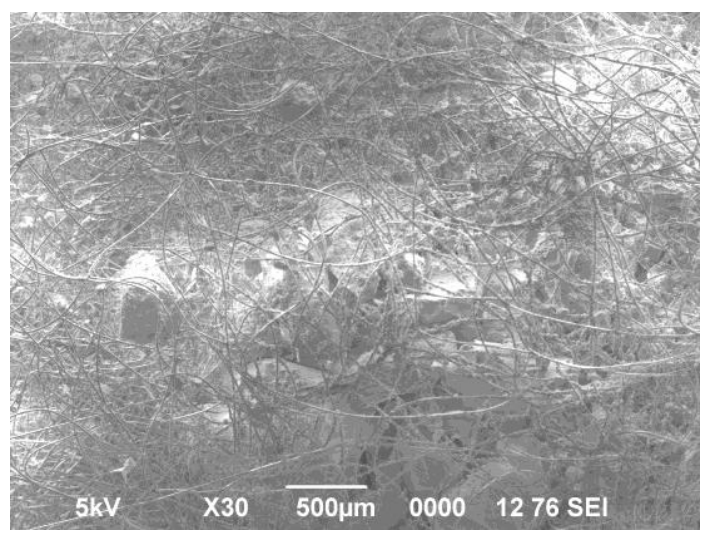

(a)

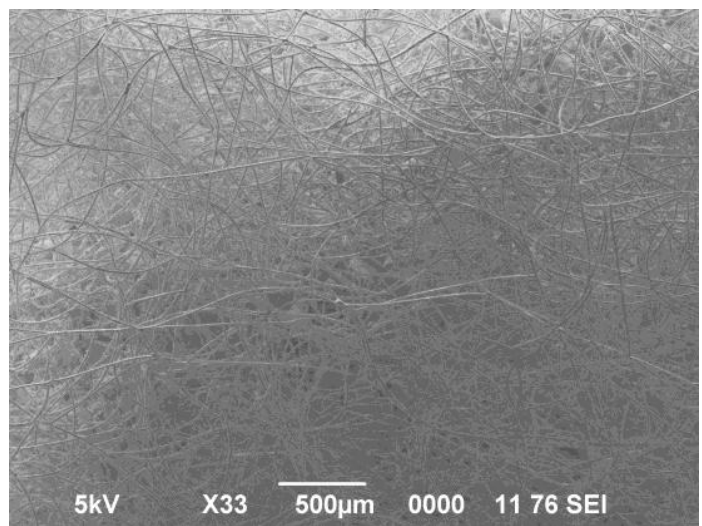

(b) 


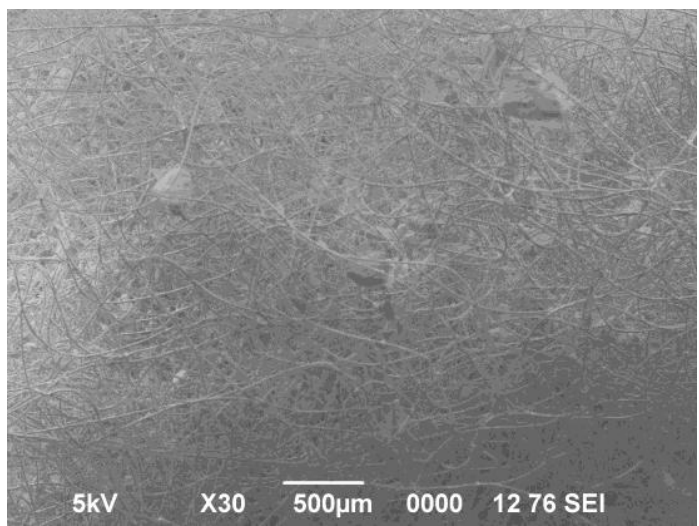

(c)

Figure 17 SEM micrographs of $\mathrm{AC}$ aged at $65.6^{\circ} \mathrm{C}$ and $90 \% \mathrm{RH}$ for (a) 0 time, (b) 1 week, (c) 5 weeks

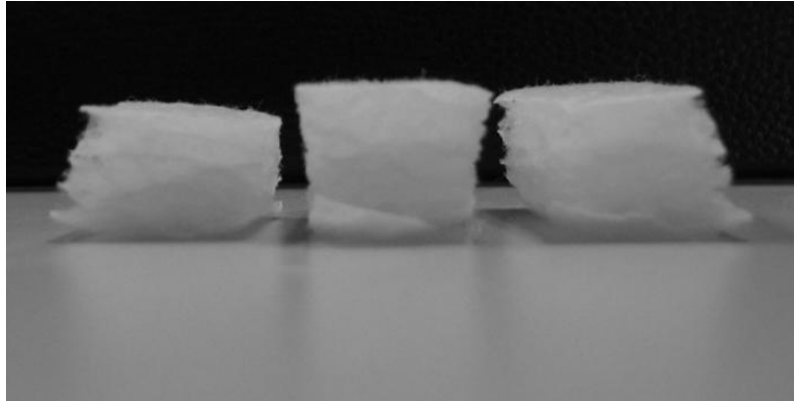

Figure 18 Comparison of AC samples before exposure (left) with 1 and 5 weeks of exposure at $65.5^{\circ} \mathrm{C}$ and $90 \% \mathrm{RH}$ (middle and right, respectively) 